\title{
Statistical Differences of Quasigeostrophic Variables, Stability, and Moisture Profiles in North American Storm Tracks
}

\author{
Andrew E. Mercer And Michael B. Richman \\ Cooperative Institute for Mesoscale Meteorological Studies, and School of Meteorology, University of Oklahoma, Norman, Oklahoma
}

(Manuscript received 6 October 2005, in final form 19 September 2006)

\begin{abstract}
Three common synoptic storm tracks observed throughout the United States are the Alberta Clipper, the Colorado cyclone, and the East Coast storm. Numerous studies have been performed on individual storm tracks analyzing quasigeostrophic dynamics, stability, and moisture profiles in each. This study evaluated storms in each track to help diagnose patterns and magnitudes of the aforementioned quantities, documenting how they compare from track to track. Six diagnostic variables were computed to facilitate the comparison of the storm tracks: differential geostrophic absolute vorticity advection, temperature advection, $\mathbf{Q}$-vector divergence, mean layer specific humidity, low-level stability, and midlevel stability. A dataset was compiled, consisting of 101 Alberta Clippers, 165 Colorado cyclones, and 159 East Coast cyclones and mean fields were generated for this comparison. Maxima and minima of the 25th and 75th percentiles were generated to diagnose magnitudes and patterns of strong versus weak cyclones and measure their similarities and differences to the mean patterns. Alberta Clippers were found to show the weakest magnitude of quasigeostrophic variables, while East Coast storms had the strongest magnitudes. Alberta Clippers maintained the lowest moisture content through their life cycle as well. However, East Coast storms were the most stable of the three tracks. Typically, correlations between storm tracks were high; suggesting that storm evolution is similar between tracks, in terms of the patterns of diagnostic variables measured. However, significant magnitude differences in the quasigeostrophic variables distinguished the storms in each track.
\end{abstract}

\section{Introduction}

Knowledge of the intensity and path of synoptic cyclones is of value to those with interest in synoptic events and those who are impacted by such cyclones. A common manner in which storms have been investigated by synopticians is through the use of case studies. Such research has been performed on synoptic events to diagnose the components of the quasigeostrophic omega equation (e.g., Gyakum 1983, 1991; Keshishian and Bosart 1987; among others). Numerous investigators have used case studies to analyze moisture and stability of individual synoptic events as well, including Marshment and Horn (1986), who examined moisture content and stability for Colorado storms and Gyakum (1983), who investigated the stability profiles of a par-

\footnotetext{
Corresponding author address: Dr. Michael B. Richman, Cooperative Institute for Mesoscale Meteorological Studies, and School of Meteorology, University of Oklahoma, 120 David L. Boren Blvd., Suite 5900, Norman, OK 73072-7307.

E-mail:mrichman@ou.edu
}

ticularly strong East Coast storm. Climatological studies, such as those by Bowie and Weightman (1914), Reitan (1974), Whittaker and Horn (1981, 1984), Bierly and Harrington (1995), and Zishka and Smith (1980), determined several key regions for synoptic storm development and propagation, referred to as storm tracks. Three key storm tracks were identified by Whittaker and Horn (1981): the Alberta Clipper (AB), the Colorado cyclone (CO), and the East Coast cyclone (EC). Historically, most work concentrated on a single storm track (Bosart 1981; Hutchinson 1995; Bosart and Lin 1984; Sanders 1987; Schultz and Doswell 2000). In contrast, Richman et al. $(1991,1992)$ analyzed precipitation patterns associated with the same three storm tracks discussed in Whittaker and Horn (1981), two of very few comparative storm track studies prior to this work.

The goal of this work is to determine differences in mean fields of six diagnostic variables of three synoptic cyclone types, as well as to diagnose the evolution of the cyclones as they move in time. The present investigation will examine if it is possible to distinguish between cyclones in the different tracks by examination of

DOI: 10.1175/MWR3395.1

(C) 2007 American Meteorological Society 
the quasigeostrophic dynamics, the stability profiles, and the moisture profiles of storms within each track. Since no comparative study of these properties of storm tracks has been carried out, the authors hope to document any major differences that may exist between the tracks and find features that set apart each of the different tracks. Specifically, differences in diagnostic variable intensity and spatial orientation are analyzed. Section 2 contains a description of the data and methods, listing all diagnostic variables and the statistical equations used to compute the mean fields and the quartiles. Section 3 describes all results arranged by the six diagnostic variables, as well as a diagnosis of variability in maxima and minima of the quartiles of the diagnostic variables. A summary of results and conclusions is contained in section 4 .

\section{Data and methods}

\section{a. Data and case selection}

Storm tracks were derived from a dataset available from the Climate Diagnostics Center (CDC), which was created from the National Centers for Environmental Prediction-National Center for Atmospheric Research (NCEP-NCAR) reanalysis (Kalnay et al. 1996) data. The algorithm used for creating this storm track dataset is summarized within Serreze et al. (1995, 1997). Data were available from 1955 to 1998 in 6-h temporal intervals. A storm was selected when it maintained a closed circulation from at least $12 \mathrm{~h}$ prior to the lowest surface pressure $\left(t_{-12}\right)$ to at least $6 \mathrm{~h}$ after lowest pressure $\left(t_{+6}\right)$. Such cyclones were tracked visually in the three general regions shown in Fig. 1. These criteria led to an uneven seasonal distribution of cases used in the study, with about $20 \%$ of the AB cyclones in the summer months versus $3 \%-5 \%$ in the summer months for the $\mathrm{CO}$ and EC cyclones. Accordingly, several summer cases were dropped from the $\mathrm{AB}$ cyclone case list at random in order to eliminate seasonal biases in the results. After that, application of the criteria led to a total of $101 \mathrm{AB}, 159 \mathrm{EC}$, and $165 \mathrm{CO}$ cyclones.

Hodges et al. (2003) conducted a study in which three different reanalysis datasets were compared in terms of track density (number of tracks per region). One dataset was based on the European Centre for Medium-Range Weather Forecasts (ECMWF) model (Gibson et al. 1997), another was based on the NCEP Department of Energy (DOE) reanalysis dataset (Kanamitsu et al. 1999), and the final was based on the NCEP-NCAR reanalysis data (Kalnay et al. 1996). Hodges et al. (2003) found that all datasets were similar in track density (number of storms per spatial unit) and therefore, no particular one is superior. Thus, NCEP-

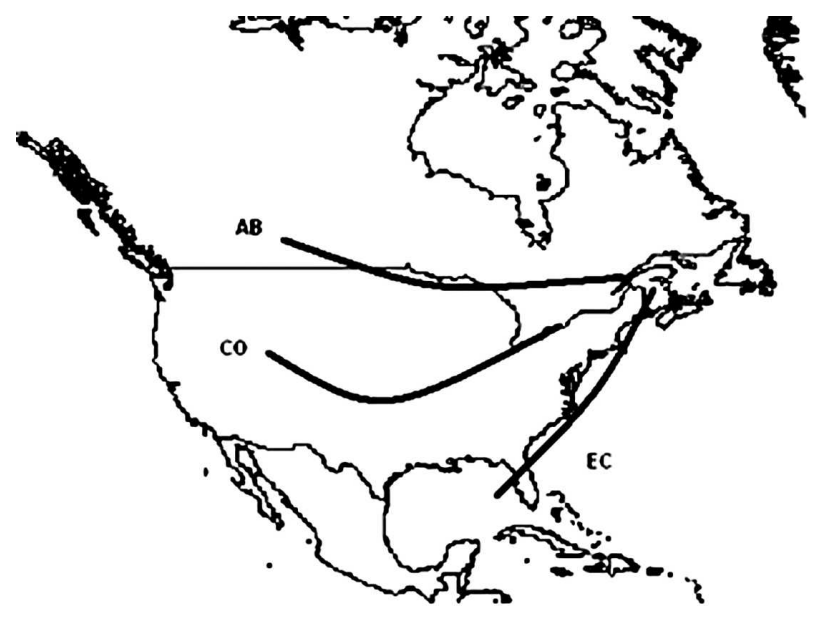

FIG. 1. Plot of three different storm tracks used herein: the Alberta Clipper (AB) track, the Colorado cyclone (CO) track, and the East Coast (EC) cyclones (from Whittaker and Horn 1981).

NCAR reanalysis data was selected for the raw variable extraction since it was used for creation of the CDC storm track dataset. Raw variables were extracted from the dataset at numerous pressure levels on a $2.5^{\circ}$ latitude-longitude grid for most of North America. According to Kalnay et al. (1996), the reanalysis dataset can be divided into several classes based on the influence of observational data and model-derived data. Most variables used in the study were classified as "A" variables (temperature, height, vorticity, wind, others), meaning that they were based on observations and were most reliable. The sole exception was specific humidity, which was classified as a "B" variable and required more model input into the computation. Despite this classification for specific humidity, its inclusion was deemed important to diagnose the moisture profiles for the cyclones.

\section{b. Diagnostic variables}

Numerous investigators have applied the quasigeostrophic omega equation to diagnose vertical motion and precipitation patterns in synoptic storms (Gyakum 1983; Lupo et al. 1992; among others). Guided by these studies, three quasigeostrophic diagnostic variables were selected. The quasigeostrophic omega equation is defined as (Bluestein 1992)

$$
\begin{aligned}
\left(\nabla_{p}^{2}+\frac{f_{0}^{2}}{\sigma} \frac{\partial^{2}}{\partial p^{2}}\right) \omega= & -\frac{f_{0}}{\sigma} \frac{\partial}{\partial p}\left[-\mathbf{V}_{g} \cdot \nabla_{p}\left(\zeta_{g}+f\right)\right] \\
& -\frac{R}{\sigma p} \nabla_{p}^{2}\left(-\mathbf{V}_{g} \cdot \nabla_{p} T\right),
\end{aligned}
$$


where $\omega$ represents vertical motion, the first term on the right-hand side is the differential geostrophic absolute vorticity advection, and the second term on the right-hand side is the Laplacian of the temperature advection. Static stability in this equation is represented by $\sigma$, and $f_{0}$ denotes the Coriolis parameter. Differential geostrophic absolute vorticity advection and temperature advection were included at different levels as they appear in (1). Computations of absolute geostrophic vorticity were performed at 400 and $600 \mathrm{hPa}$ using the curl of the geostrophic wind components. The geostrophic wind components were computed from the height field in the reanalysis and the following equation from Bluestein (1992):

$$
\mathbf{V}_{g}=\frac{1}{f} \hat{k} \times \nabla \Phi .
$$

In turn, these two levels were used to determine the differential geostrophic absolute vorticity advection. Differential geostrophic absolute vorticity advection has been analyzed often in synoptic literature, including case studies by Bell and Bosart (1993) and Pagnotti and Bosart (1984). Temperature advection was examined in case studies performed by Bell and Bosart (1994), Pagnotti and Bosart (1984), Rolfson and Smith (1996), and by many other synopticians.

Hoskins et al. (1978) noted that temperature advection and differential geostrophic absolute vorticity advection tend to oppose each other in certain synoptic situations, but the resulting vertical motion remained unchanged. To identify the region of vertical motion without using temperature or differential vorticity advection, Hoskins et al. (1978) formalized the parameter called the $\mathbf{Q}$ vector. This quantity was defined by Bluestein (1993) as

$$
\mathbf{Q}=-\frac{R}{p \sigma}\left(\begin{array}{l}
\frac{\partial \mathbf{v}_{g}}{\partial x} \cdot \nabla_{p} T \\
\frac{\partial \mathbf{v}_{g}}{\partial y} \cdot \nabla_{p} T
\end{array}\right)=\left(\begin{array}{l}
Q_{1} \\
Q_{2}
\end{array}\right) .
$$

When applying the $\mathbf{Q}$ vector to the quasigeostrophic omega equation, the following results:

$$
\left(\nabla_{p}^{2}+\frac{f_{0}^{2}}{\sigma} \frac{\partial^{2}}{\partial p^{2}}\right) \omega=-2 \nabla_{p} \cdot \mathbf{Q} .
$$

Thus, a direct relationship between the vertical motion and the divergence of the $\mathbf{Q}$ field exists (i.e., $\mathbf{Q}$-vector convergence represents rising motion). When computing $\mathbf{Q}$-vector divergence, a value of static stability is required. The equation for static stability includes a term that accounts for the vertical variation of potential temperature but, for this study, this term was neglected due to the coarseness of the reanalysis grid $(\mathrm{H}$. B. Bluestein 2005, personal communication), leading to this simplified expression for the $\mathbf{Q}$ vector:

$$
\mathbf{Q}=-\frac{R}{p}\left(\begin{array}{l}
\frac{\partial \mathbf{v}_{g}}{\partial x} \cdot \nabla_{p} T \\
\frac{\partial \mathbf{v}_{g}}{\partial y} \cdot \nabla_{p} T
\end{array}\right)=\left(\begin{array}{c}
Q_{1} \\
Q_{2}
\end{array}\right) .
$$

This was a safe approach since static stability is a constant that can be divided out of the resulting $\mathbf{Q}$ vectors without changing the orientations of the vectors.

The $\mathbf{Q}$ vector provided insight into the forcing for vertical motion of the cyclone at any single level. This parameter was used in numerous synoptic studies (e.g., Boyle and Bosart 1986; Jusem and Atlas 1998; Barnes 1986; Keshishian and Bosart 1987, etc.) for diagnosis of quasigeostrophic dynamics and associated vertical motion. Sanders and Hoskins (1990) provided a method for easy estimation of $\mathbf{Q}$ vectors from weather maps, which was used to verify the results presented herein. Keyser et al. (1992) used numerical simulations to determine how well $\mathbf{Q}$-vector divergence relates to quasigeostrophic vertical motion and were able to show how significant the $\mathbf{Q}$ vector is in diagnosing synoptic events.

Vertical differences in potential temperature and layer-averaged specific humidity were selected as variables to measure the stability of the atmosphere and the moisture content. Stability was computed as a difference between a low-level and an upper-level potential temperature. This calculation led to negative values, with numbers closer to zero representing a smaller vertical change in potential temperature and a more unstable region. Stability was computed over a lower atmosphere layer $(700-850 \mathrm{hPa}$ ) and a midatmosphere layer $(700-500 \mathrm{hPa})$. Other levels were considered, but the data became contaminated with stratospheric air above $400 \mathrm{hPa}$; therefore, no other levels were used. Specific humidity, defined as the ratio of the mass of vapor over the mass of the entire volume, was calculated at three low levels $(925,850$, and $700 \mathrm{hPa})$, and a mean was taken over these three layers to obtain a mean pattern for low-level moisture content. Specific humidity was selected as the moisture parameter as its definition between different layers remained consistent. Moisture content was negligible at mid- and upper levels, so these were not included. All diagnostic variables were computed using the Grid Analysis and Display System (GrADS; COLA 2005)

\section{c. Statistical methodology}

Mean fields were generated over a 35-point grid centered at the grid point of lowest pressure, leading to a 
TABLE 1. Number of cases used for each temporal point in each storm track type.

\begin{tabular}{crrcr}
\hline \hline Storm type & $t_{-24}$ & $t_{-12}$ & $t_{0}$ & $t_{+12}$ \\
\hline AB & 88 & 101 & 101 & 82 \\
CO & 140 & 165 & 165 & 149 \\
EC & 148 & 159 & 159 & 129 \\
\hline
\end{tabular}

$12.5^{\circ}$ latitude $\times 17.5^{\circ}$ longitude $(5 \times 7$ grid points $)$ movable grid. This grid size was chosen to ensure no additional significant low pressure cyclone, independent of the analyzed cyclone, would contaminate the dataset. Cyclones were tracked through four points in a temporal sequence: $24 \mathrm{~h}$ prior $\left(t_{-24}\right)$ to the lowest surface pressure, $12 \mathrm{~h}\left(t_{-12}\right)$ prior to the lowest surface pressure, the time of the lowest surface pressure $\left(t_{0}\right)$, and $12 \mathrm{~h}$ subsequent $\left(t_{+12}\right)$ to the lowest pressure. This methodology provided a Lagrangian framework for calculation of diagnostic variables and eliminated any statistical biases that may have resulted from a geographical tracking method (i.e., a possible lack of cyclones in some regions where the track does not exist frequently). Not all cyclones could be tracked from $t_{-24}$ to $t_{+12}$, but all cyclones that could be tracked from $t_{-12}$ to $t_{+6}$ were included to maintain a large dataset for computation of representative statistics. Table 1 lists the number of storms kept for each of the four temporal intervals used for each track. This methodology allowed for the most data input for $t_{-12}$ and $t_{0}$, the two occasions shown to be the most dynamically active throughout the storm track. Another potential problem minimized by this methodology is the underestimation of the cyclone intensity by the reanalysis due to the poor handling of lee cyclogenesis in the lee of the Rockies. Tracks derived for the $\mathrm{AB}$ and $\mathrm{CO}$ cyclones do not reach their lowest pressure until they are well east of the influence of the Rocky Mountains, so no lee cyclogenesis impacted the results.

Permutation tests (Mercer 2005) were performed using S-Plus (Insightful Corporation 2002) on the resulting datasets on a gridpoint-by-gridpoint basis. Wilks (1995) defines a permutation test as "the specific probability that the observed value (magnitude) of the test statistic, together with all others at least as unfavorable to the null hypothesis, will occur according to the null distribution." Simply stated, the permutation test compares two vectors of data (e.g., AB and CO 850-hPa temperature advection) and determines if their magnitudes are statistically different. Resulting $p$ values from the permutation test represent the statistical significance of the difference. Typically, $p$ values less than 0.05 are considered statistically significant; thus, grid points exhibiting $p$ values less than 0.05 contained sig- nificantly different magnitudes. Permutation tests were based on 1000 replications for all diagnostic variables to analyze magnitude differences in the fields between tracks.

Correlations have been used to search data for significant regions of spatial orientation difference. Klein (1951) used lag correlations on sea level pressure to determine patterns in the fields. A diagnosis of variability was performed in Klein's paper, although standard deviation was used in that work, instead of the empirical percentiles used herein. Wichansky and Harnack (2000) employed correlations to compare several different diagnostic variables to the duration of winter precipitation in a sample of EC cyclones, including several common to this study. In the present study, correlation coefficients were computed between tracks over the same diagnostic variable to search for spatial commonalities and differences between the tracks. Additionally, correlations were computed between the percentile fields and the mean field to determine how representative the quartile fields are with respect to the mean.

The 25th and 75th percentiles, known as the first and third quartiles, were generated over the same 35 gridpoint region to diagnose variability in the storm tracks. Typically, the median is compared to these quartiles (Wilks 1995); however, mean fields were used in this study since the data have been quality controlled to determine if outliers existed. A preliminary analysis was undertaken to investigate if the mean patterns were affected adversely by outliers. A cluster analysis (Stooksbury and Michaels 1991; Konrad 1997) was performed using a Euclidian distance of 0.004 units of the given diagnostic variable as a filter. This threshold was selected as most clusters within the cluster analysis maintained a Euclidian distance smaller than 0.004 units based on a visual analysis of the resulting dendrogram (Wilks 1995). Cyclones with a larger Euclidian distance were culled, and new mean fields were generated. Analyses of these trimmed mean fields against the untrimmed mean fields revealed no significant difference; hence, the mean was deemed centered in the distribution of storm tracks and all cyclones were included.

Quartiles were computed at each of the 35 grid points for $t_{0}$, the most dynamically active period in the track. Then, maximum and minimum gridpoint values of each quartile field were extracted and compared with maximum and minimum gridpoint values of the mean to diagnose the magnitude differences of the strong and weak cyclones, compared with the mean cyclone. These comparisons were not trivial due to the nature of the data, as the three quasigeostrophic variables existed as 


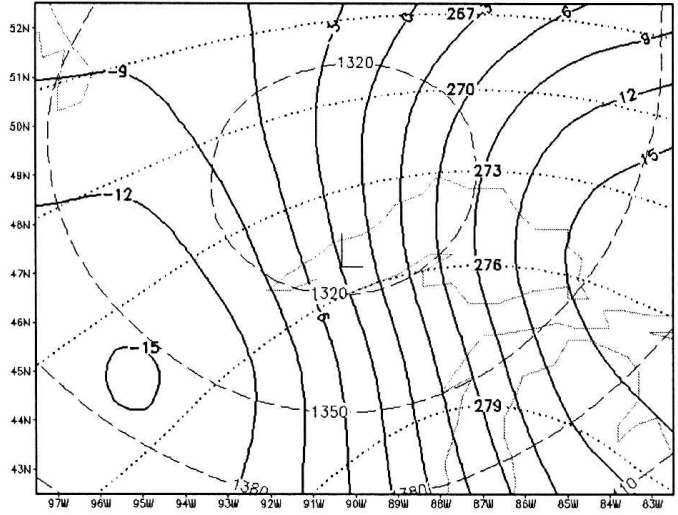

(a)

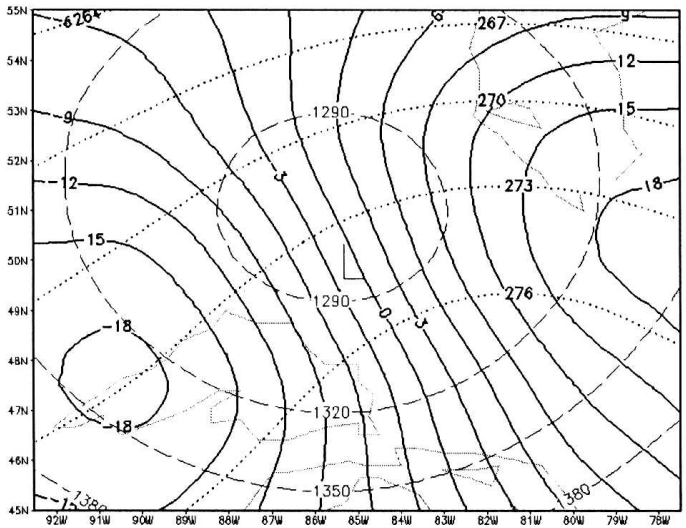

(b)

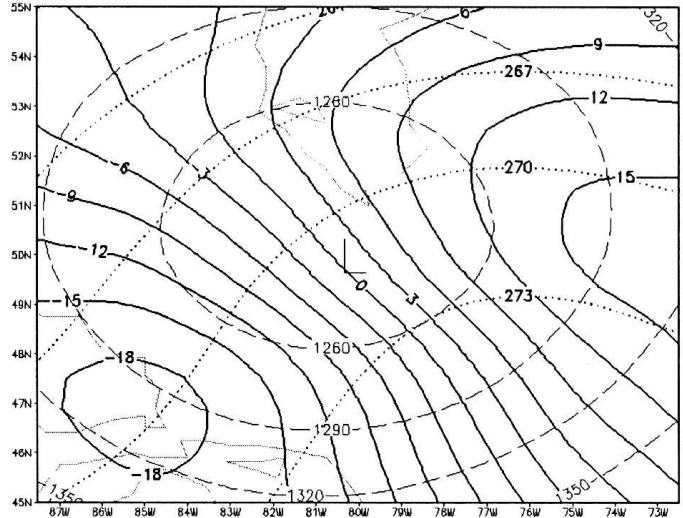

(c)

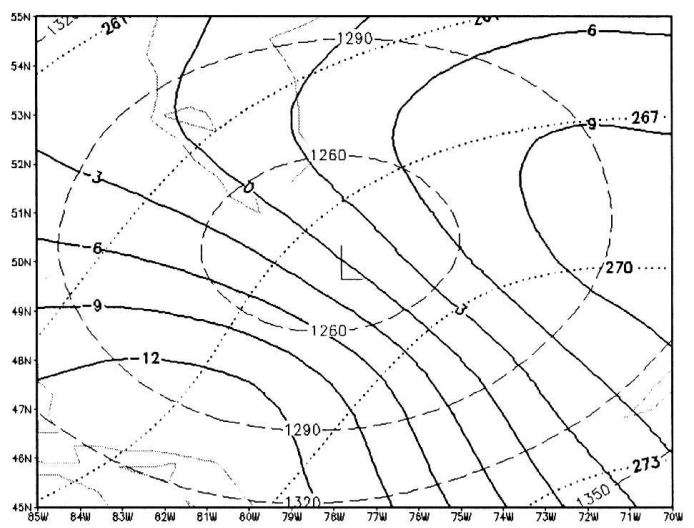

(d)

FIG. 2. Mean temperature advection profiles for the AB cyclones: (a) $t_{-24}$, (b) $t_{-12}$, (c) $t_{0}$, and (d) represents $t_{+12}$. Dotted contours are isotherms in $\mathrm{K}$, solid lines represent temperature advection in $10^{-5} \mathrm{~K} \mathrm{~s}^{-1}$, and dashed lines are height lines in $\mathrm{m}$.

both positive and negative values. To diagnose variability and determine the magnitudes of the strong and weak storms for these variables, a combination of the quartiles is needed. The strongly positive values of the third quartile combined with the strongly negative values of the first quartile represent the stronger storms, while the weakly positive values of the first quartile combined with the weakly negative or possibly weakly positive values of the third quartile represent the weak storms. Stability and moisture fields were easier to diagnose as they only existed as a positive or negative quantity, but not as both.

\section{Results}

\section{a. Temperature advection fields}

The first diagnostic variable computed was the mean temperature advection at $850 \mathrm{hPa}$. A maximum of warm air advection (WAA) was present in the AB cyclones (Fig. 2) throughout their entire temporal se- quence. Southerly $850-\mathrm{hPa}$ flow ahead of the $850-\mathrm{hPa}$ cyclone was attributed to the maximum of WAA ahead of the cyclone, and the spatial location of the maximum WAA due east of the surface low was consistent with the expected precipitation pattern of the $\mathrm{AB}$ storm. Magnitudes of the AB WAA increased with time up to $t_{0}$ (Fig. 2c), a result attributed to increasing southerly flow and a larger baroclinicity present on the eastern half of the $\mathrm{AB}$ cyclone. Cold air advection (CAA) within the $A B$ cyclones maintained a spatial location southwest of the surface low through all times in the $\mathrm{AB}$ track. Although CAA increased to $t_{0}$ within the $\mathrm{AB}$ cyclones, magnitudes of CAA showed little variation from $t_{-24}$ (Fig. 5a). Due to the northward location of the $\mathrm{AB}$ cyclone and the apparent decrease in the meridional thermal gradient with increasing latitude, only slight changes ( $20 \%$ or less) in magnitude were noted for CAA throughout the temporal evolution of the mean cyclone. One case study of an $\mathrm{AB}$ cyclone (Servranckx 1988) showed a region of maximum CAA and ensuing low-level divergence southwest of the sur- 


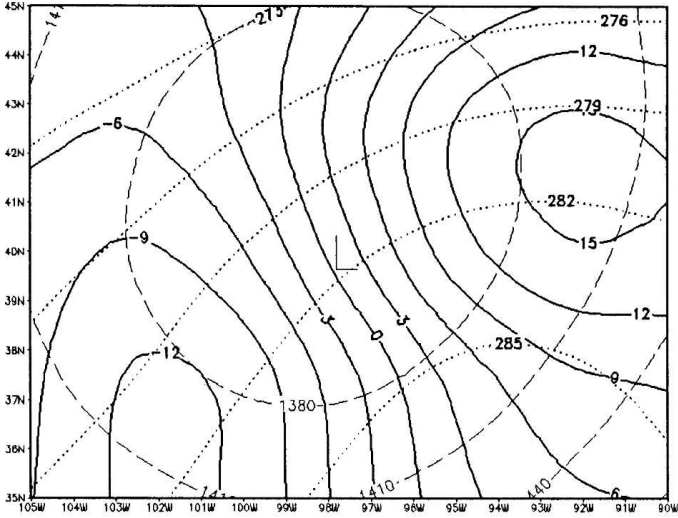

(a)

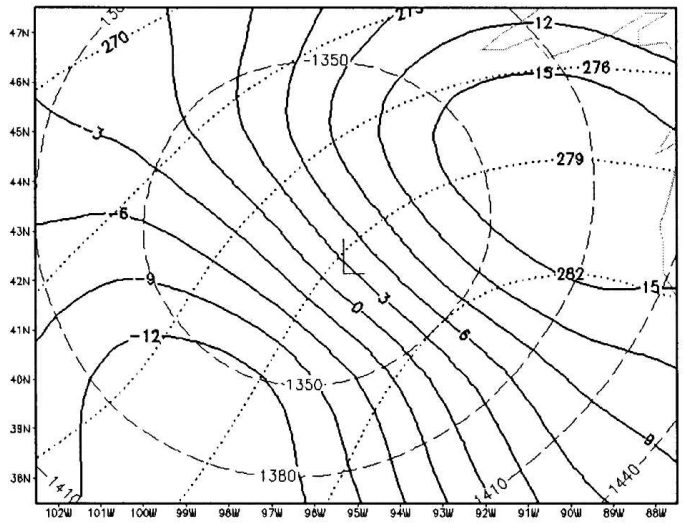

(b)

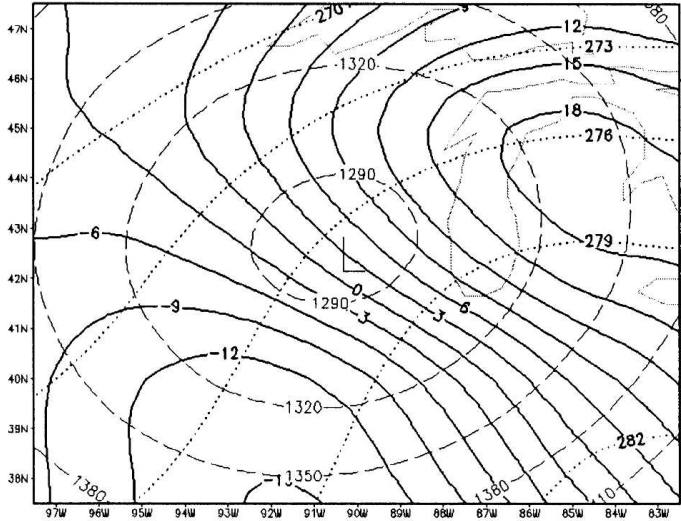

(c)

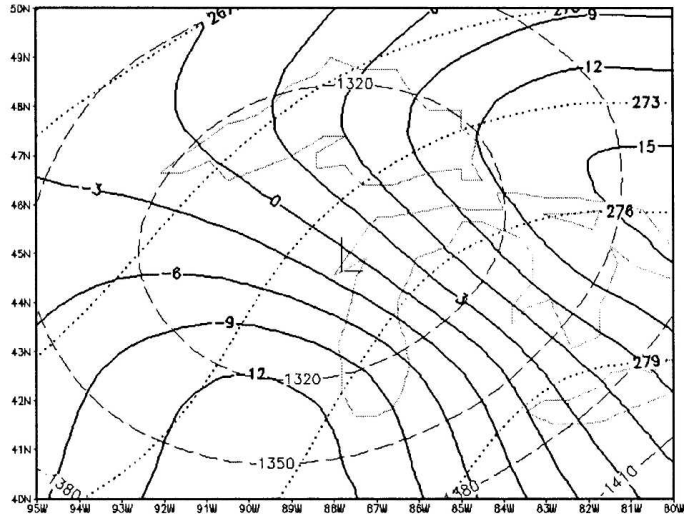

(d)

FIG. 3. Same as in Fig. 2, but for the CO cyclones.

face low, which is supported herein for a large sample by the resulting mean $\mathrm{AB}$ cyclone.

In the $\mathrm{CO}$ cyclone (Fig. 3), a maximum of WAA was present northeast of the surface low throughout the entire temporal sequence of the cyclone. WAA increased by $t_{-12}$ (Fig. 3b) due to the increase in the height gradient associated with the strengthening cyclone. Colder air intrusion into the cyclone led to a gradual weakening of the thermal gradient by $t_{0}$ (Fig. 3c) and, by $t_{+12}$ (Fig. 3d), the maximum low-level WAA had swept eastward along with the weakened $850-\mathrm{hPa}$ cyclone. A slightly southward turn was noticeable in the WAA maximum by $t_{+12}$, a result running counter to Bierly and Harrington (1995) who noted a significant northward turn during the spring and fall months. This discrepancy was attributed to the mean storm track in this study encompassing the entire year instead of a seasonal breakdown, and suggests a more southerly turn to the $\mathrm{CO}$ cyclone during the winter and summer months. The maximum CAA for the $\mathrm{CO}$ cyclone was positioned southwest of the surface low and progressed eastward with time, strengthening slightly from $t_{-24}$ to $t_{-12}$ followed by a gradual weakening of the magnitude.
Stronger CAA at $t_{-12}$ (Fig. 3b) corresponded with more intense WAA at the same time, suggesting that the increased storm strength and associated wind field were impacting both thermal advection regions. The maximum CAA shifted eastward with time as well, evidence of the advancing $850-\mathrm{hPa}$ cold front and its associated thermal gradient. Overall, thermal advection regions within the $\mathrm{CO}$ cyclones followed paths predicted by quasigeostrophic theory and the associated precipitation patterns. Moreover, it is in agreement with a study by Keshishian et al. (1994) that followed the frontal and thermal life cycle of a small composite of the $\mathrm{CO}$ cyclones.

For the EC cyclone (Fig. 4), several key regions of significance were noted. EC cyclones maintained a maximum of WAA, similar to that of the CO cyclones, northeast of the surface low throughout the entire storm cycle. WAA intensity was sustained from $t_{-24}$ (Fig. 4a) to $t_{0}$ (Fig. 4c) but, as with the CO cyclones, the maximum propagated eastward with time. The eastward turn in the storm motion was consistent in the vertical forcing profile provided by the shifting WAA maximum as well. This result was in accord with nu- 


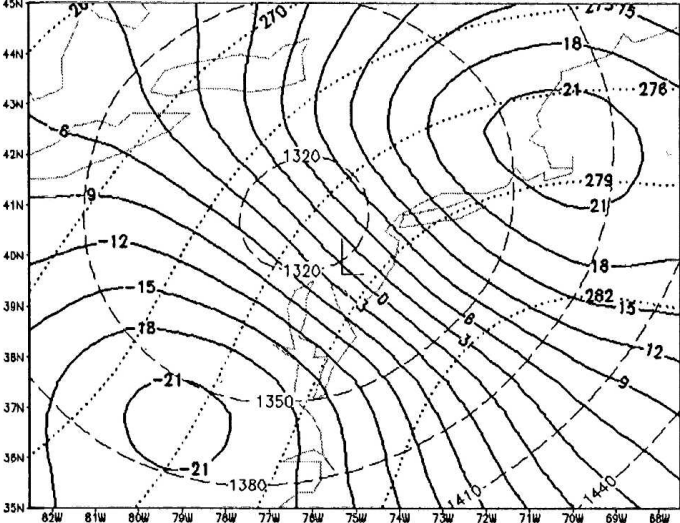

(a)

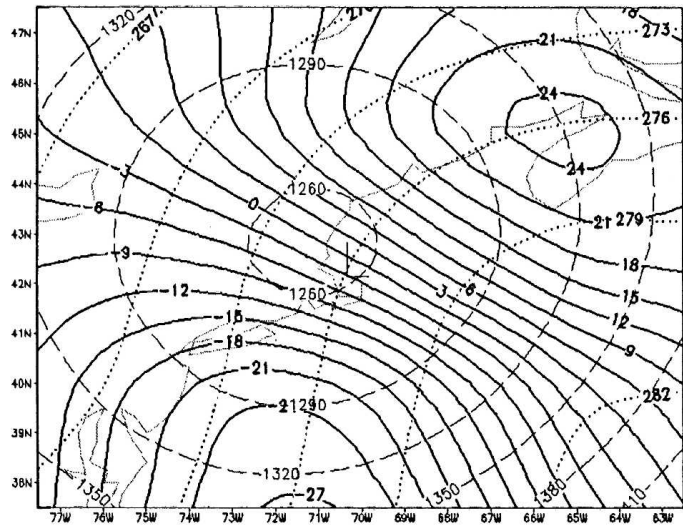

(b)

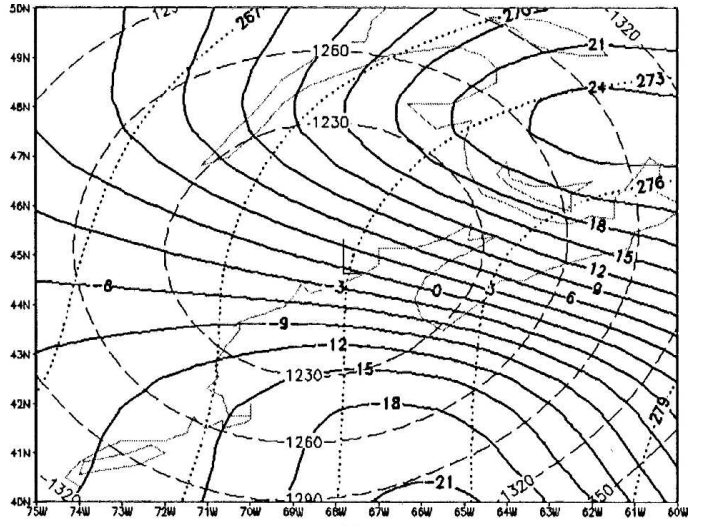

(c)

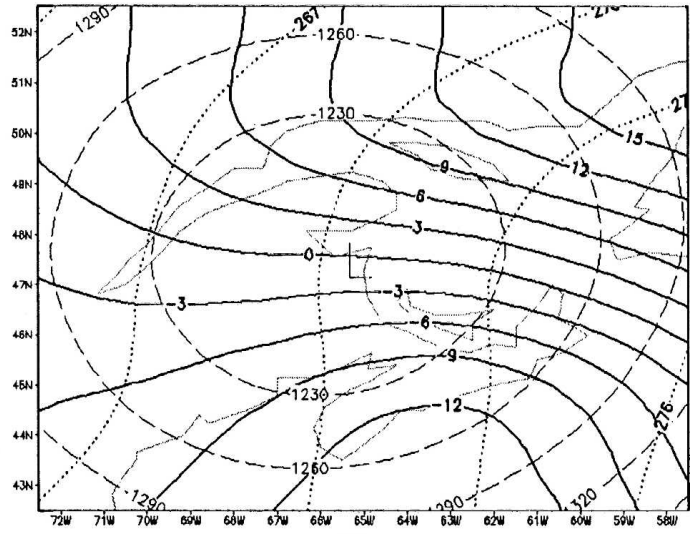

(d)

FIG. 4. Same as in Fig. 2, but for the EC cyclones.

merous EC studies (e.g., Gyakum 1983, 1991; Gyakum et al. 1992; among others). The CAA maximum advanced eastward with time across the southern third of the EC cyclone domain, and the CAA strengthened through $t_{-12}$ (Fig. 4b) as well. Between $t_{-12}$ and $t_{0}$, a noticeable decrease in mean CAA magnitude was noted (roughly $25 \%$ ) and the strong wind field, associated with the significant $850-\mathrm{hPa}$ cyclone, shifted the maximum in CAA to south-southeast of the surface low. This abnormally large shift in the CAA maximum was evidence of a tightly wrapped and a robust cyclone dynamically (i.e., a strong thermal gradient and significant wind field). By $t_{+12}$ (Fig. 4d), the CAA maintained a position south-southeast of the surface low, but the magnitude of the CAA continued to decrease in association with the weakening storm. This significant eastward surge in the CAA maximum was evident in several EC studies, including that of Boyle and Bosart (1986), which analyzed a significant EC event from March 1971.

A quantitative comparison between the diagnostic variables in storm tracks was accomplished through an analysis of the correlation coefficients and the $p$ values from the permutation tests. Numerical results from the permutation tests are given herein. As suggested by the large correlations between the $\mathrm{AB}$ and $\mathrm{CO}$ cyclones (Table 2a), both fields should vary little spatially and maintain a similar orientation throughout their temporal sequence (correlations were in excess of 0.95 ). This result is consistent with geographic location, as both the $\mathrm{AB}$ and $\mathrm{CO}$ cyclones originate along the same longitudinal region. Interestingly, Keshishian et al. (1994) analyzed both the $\mathrm{AB}$ and $\mathrm{CO}$ cyclones and did not classify them independently, an analysis decision supported by the correlation results herein. Regions of significant magnitude difference, represented by the permutation tests, appeared primarily northwest and southeast of the surface low ( $p$ value $<0.01$ for 11 grid points; Mercer 2006).

Correlations between the $\mathrm{AB}$ and $\mathrm{EC}$ thermal advection fields were smaller than for the $\mathrm{AB}$ and $\mathrm{CO}$ fields at all times, with the maximum correlation of 0.84 observed at $t_{-24}$ and $t_{+12}$. This result stems from the locational disparity between the cyclones, as well as the differences between the mean storm intensity leading to contrasts in the thermal advection fields. These re- 
TABLE 2. Correlations between the different diagnostic variables of the three storm tracks. The rows represent one temporal interval, while the columns represent the different comparisons. Mean fields between the two listed tracks in the columns were used in the computation of the correlation coefficients: (a) temperature advection, (b) differential geostrophic vorticity advection, (c) Q-vector divergence, (d) midlevel stability, (e) low-level stability, and (f) mean layer specific humidity.

\begin{tabular}{|c|c|c|c|}
\hline \multicolumn{4}{|c|}{ (a) Temperature advection } \\
\hline & $\mathrm{AB}-\mathrm{CO}$ & $\mathrm{AB}-\mathrm{EC}$ & $\mathrm{CO}-\mathrm{EC}$ \\
\hline$t_{-24}$ & 0.95 & 0.84 & 0.95 \\
\hline$t_{-12}$ & 0.95 & 0.80 & 0.93 \\
\hline$t_{0}$ & 0.95 & 0.72 & 0.86 \\
\hline$t_{+12}$ & 0.95 & 0.84 & 0.95 \\
\hline \multicolumn{4}{|c|}{ (b) Differential absolute geostrophic vorticity advection } \\
\hline & $\mathrm{AB}-\mathrm{CO}$ & $\mathrm{AB}-\mathrm{EC}$ & CO-EC \\
\hline$t_{-24}$ & 0.96 & 0.92 & 0.95 \\
\hline$t_{-12}$ & 0.97 & 0.94 & 0.98 \\
\hline$t_{0}$ & 0.92 & 0.80 & 0.95 \\
\hline$t_{+12}$ & 0.96 & 0.92 & 0.95 \\
\hline
\end{tabular}

(c) $\mathbf{Q}$-vector divergence

\begin{tabular}{lccc}
\hline & AB-CO & AB-EC & CO-EC \\
\hline$t_{-24}$ & 0.88 & 0.79 & 0.92 \\
$t_{-12}$ & 0.94 & 0.93 & 0.98 \\
$t_{0}$ & 0.96 & 0.92 & 0.97 \\
$t_{+12}$ & 0.88 & 0.79 & 0.92 \\
\hline
\end{tabular}

(d) Midlevel stability

\begin{tabular}{lccc}
\hline & AB-CO & AB-EC & CO-EC \\
\hline$t_{-24}$ & 0.61 & 0.85 & 0.89 \\
$t_{-12}$ & 0.84 & 0.84 & 0.99 \\
$t_{0}$ & 0.94 & 0.69 & 0.89 \\
$t_{+12}$ & 0.61 & 0.85 & 0.89 \\
\hline
\end{tabular}

(e) Low-level stability

\begin{tabular}{lccc}
\hline & AB-CO & AB-EC & CO-EC \\
\hline$t_{-24}$ & 0.96 & 0.53 & 0.44 \\
$t_{-12}$ & 0.97 & 0.54 & 0.62 \\
$t_{0}$ & 0.93 & 0.77 & 0.77 \\
$t_{+12}$ & 0.96 & 0.53 & 0.44 \\
\hline
\end{tabular}

(f) Mean layer specific humidity

\begin{tabular}{lccc}
\hline & AB-CO & AB-EC & CO-EC \\
\hline$t_{-24}$ & 0.78 & 0.84 & 0.95 \\
$t_{-12}$ & 0.90 & 0.85 & 0.98 \\
$t_{0}$ & 0.89 & 0.81 & 0.97 \\
$t_{+12}$ & 0.78 & 0.84 & 0.95 \\
\hline
\end{tabular}

sults quantify differences in these tracks for the first time in synoptic literature, although the findings were not surprising due to large disparities in storm strength between the two tracks. The permutation tests revealed large statistical differences across the northern and southern thirds of the field. The $p$ values in these regions were less than 0.01 for well over half of the field, implying large magnitude differences in the fields. A comparison of the $\mathrm{CO}$ and $\mathrm{EC}$ cyclones suggested large similarities between the two thermal advection fields of these two tracks for all times except $t_{0}$. Flow in the EC cyclone at $850 \mathrm{hPa}$ resulted in larger eastward displacement of the maximum CAA region in the $\mathrm{EC}$ cyclone by $t_{0}$, leading to a lower spatial correlation between these fields at this time. Moisture sources and midlevel dynamics led to similar magnitudes of intensity in the $\mathrm{CO}$ and EC cyclones, further supported by the $p$-value fields, with the largest differences observed northeast and southwest of the surface low. This outcome, with $p<0.01$, demonstrates that the largest differences between the $\mathrm{CO}$ and EC occurs near the 850-hPa frontal boundaries, a finding hitherto unknown.

\section{b. Differential geostrophic absolute vorticity advection}

Differential geostrophic absolute vorticity advection appears explicitly in the quasigeostrophic omega equation, with cyclonic differential vorticity advection (CVA) corresponding to the rising motion and anticyclonic differential vorticity advection (AVA) corresponding to the sinking motion. The $\mathrm{AB}$ cyclones (Fig. 5) exhibited the weakest magnitudes of CVA and AVA of the three tracks. At $t_{-24}$, (Fig. 5a) a maximum of CVA was located due west of the surface low. This maximum shifted eastward with time, becoming collocated with the surface low by $t_{0}($ Fig. $5 \mathrm{c}$ ). The magnitude increased throughout this period to a maximum value by $t_{0}$. The CVA maximum, appearing slightly west of the location of the surface low, was positioned in this way due to the vertical tilt of the $\mathrm{AB}$ cyclone toward the west. Since CVA was computed between 400 and $600 \mathrm{hPa}$, it is likely that midlevel forcing was represented well by the CVA maximum, and the general eastward progression of the CVA maximum until $t_{0}$ can be attributed to the cyclone becoming more vertically stacked by the end of the temporal sequence. By $t_{+12}$ (Fig. 5d), most of the CVA had dissipated, evidence of the beginning stages of occlusion of the mean $\mathrm{AB}$ cyclone.

The CO cyclone (Fig. 6) had a profile similar to that observed with an $\mathrm{AB}$ cyclone, with a westward-displaced maximum of CVA at $t_{-24}$ shifting eastward and overtaking the surface low pressure cyclone by $t_{0}$ (Fig. 6c). A faster weakening of the midlevel vorticity maxima in the $\mathrm{CO}$ cyclones (by $t_{0}$ ) was suggested by the lower CVA values by $t_{0}$. AVA entered the domain by $t_{-12}$, hinting at the approaching anticyclone west of the cyclone. By $t_{+12}$ (Fig. 6d), the regions of CVA and AVA weakened in magnitude, a result of the gradual weakening and occlusion of the disturbance after reach- 


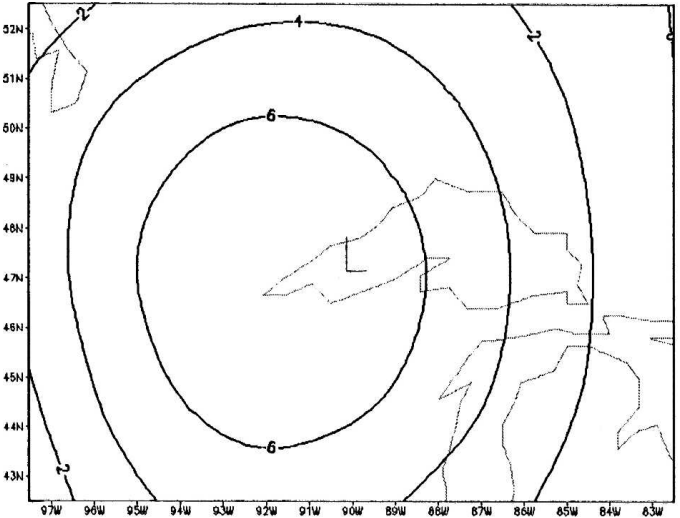

(a)

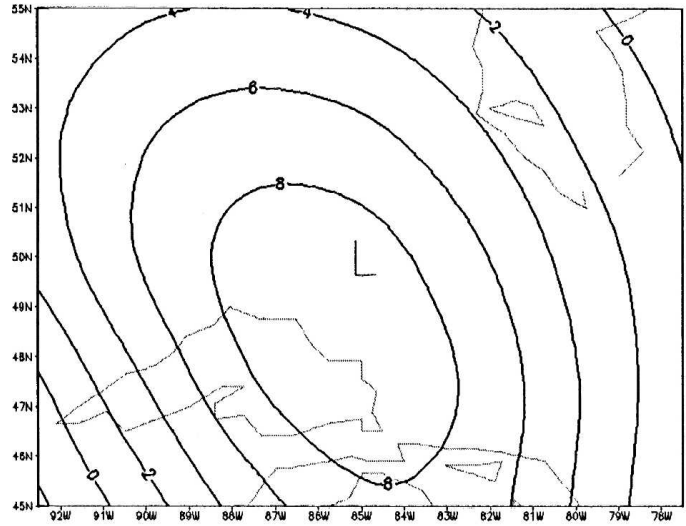

(b)

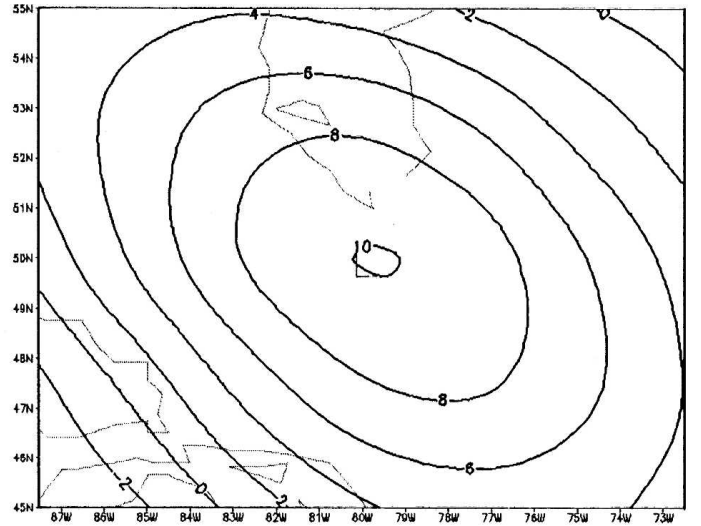

(c)

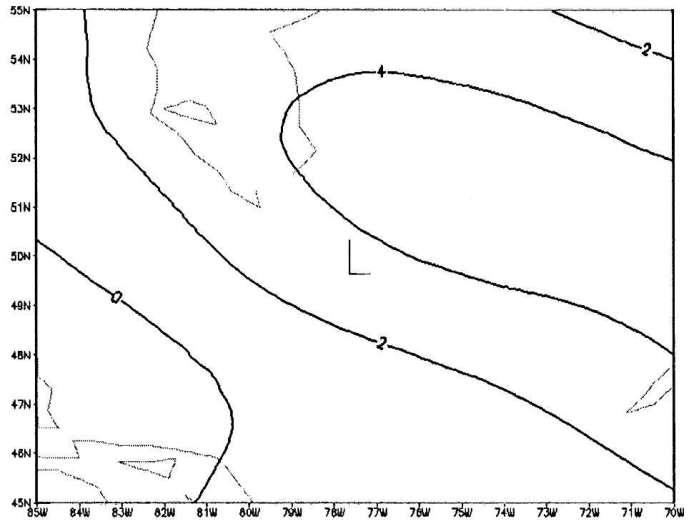

(d)

FIG. 5. Mean differential geostrophic vorticity advection profiles for the AB cyclones: (a) $t_{-24}$, (b) $t_{-12}$, (c) $t_{0}$, and (d) $t_{+12}$. Solid contours represent differential geostrophic vorticity advection in $10^{-14} \mathrm{~s}^{-1} \mathrm{~m}^{-1} \mathrm{~Pa}^{-1}$. These plots are valid for a layer between 600 and $400 \mathrm{hPa}$.

ing the lowest surface pressure. The aforementioned reasons for the motion of the CVA maximum for the $\mathrm{AB}$ cyclones apply for the $\mathrm{CO}$ cyclones as well. In a paper by Fawcett and Saylor (1965), low-level relative vorticity maxima appeared well east of the surface cyclone, implying a westward tilt with the height of the cyclone, consistent with the results herein.

CVA within the EC cyclone (Fig. 7) was on the same order of magnitude as that of the CO cyclone. CVA intensified from $t_{-24}$ (Fig. 7a) to $t_{-12}$ (Fig. 7b) west of the surface low, consistent with both the $\mathrm{AB}$ and $\mathrm{CO}$ cyclones at the same time. The shift northeast of the surface low by $t_{0}$ (Fig. 7c) of maximum CVA was faster than for the previous two storm tracks, likely caused by the more dynamic cyclone over the East Coast. CVA weakened by $t_{0}$ (almost $40 \%$ from the maximum), evidence of the occlusion and decline of the cyclone by this time. Clearly, midlevel weakening was common within all three storm tracks prior to the maximum storm depth, suggesting a delayed reaction by the surface low to processes taking place in the midlevels. CVA weak- ened considerably (an additional $40 \%$ ) by $t_{+12}$ (Fig. 7d), a direct result of the weakening midlevel cyclone. Sanders (1987) performed a climatology of EC cyclones and their associated cyclogenesis resulting from absolute vorticity advection at $500 \mathrm{hPa}$, and showed that vorticity advection is a necessary condition for EC cyclogenesis and that vorticity maxima tended to "catch up" with the surface low in time.

Correlations between the three tracks (Table 2b) in terms of absolute vorticity advection were high for all times and all tracks $\left(>0.9\right.$ for all except AB-EC at $\left.t_{0}\right)$. These high correlations are a consequence of the typical strengthening and eastward shift of the vorticity maxima through $t_{-12}$, followed by a general weakening of magnitude and shifting of the CVA maximum to directly over or slightly east of the surface low. Faster storm motion associated with the EC cyclone versus the $\mathrm{AB}$ cyclone led to the lower correlation at $t_{0}$ of 0.8 , the only correlation less than 0.9 associated with this variable. The permutation tests on this variable revealed many similarities between the magnitudes of the vor- 


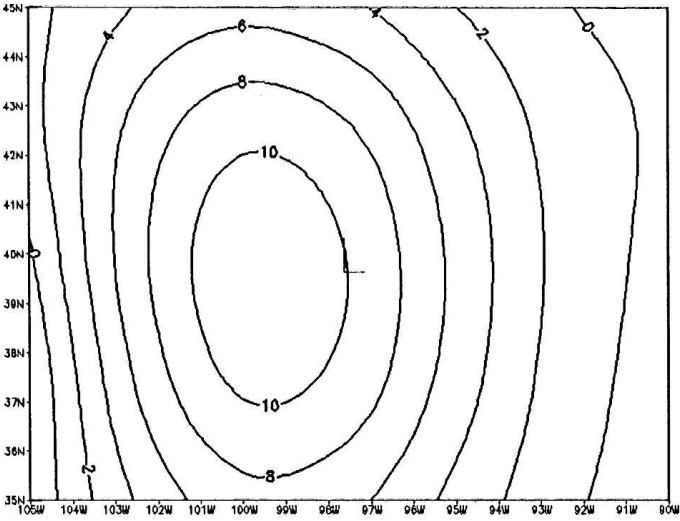

(a)

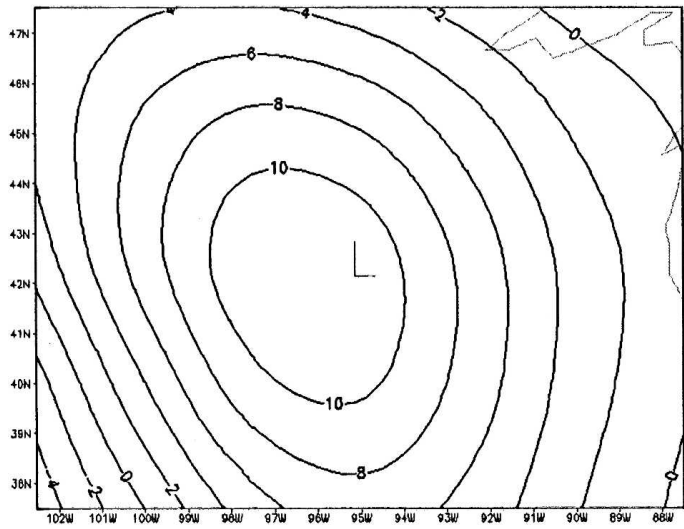

(b)

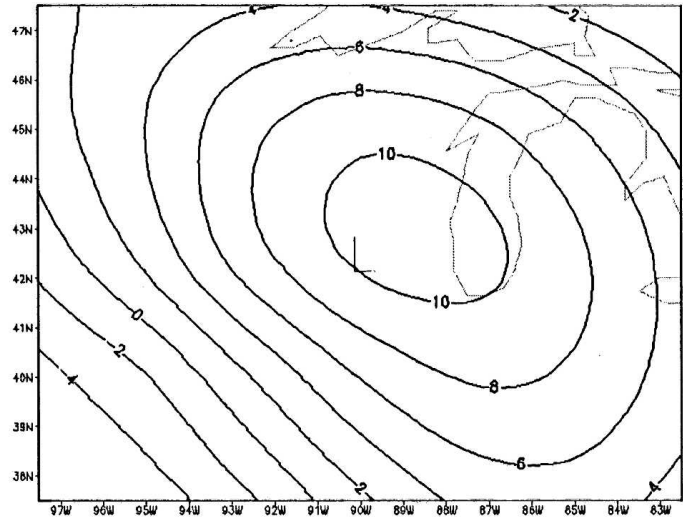

(c)

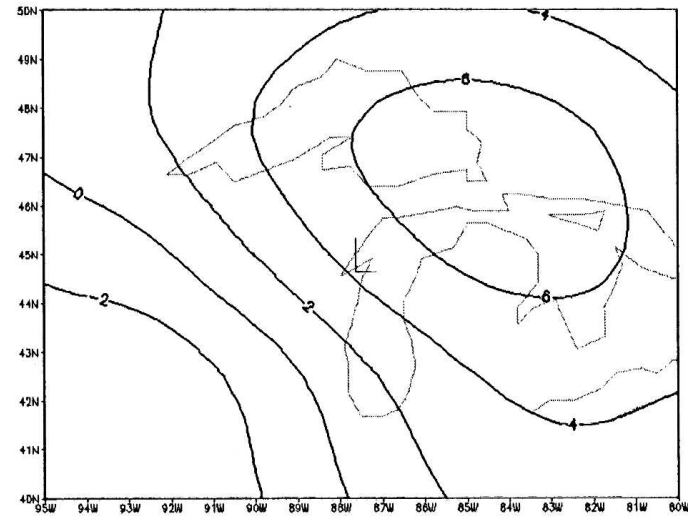

(d)

FIG. 6. Same as in Fig. 5, but for the CO cyclones.

ticity advection in the three tracks. The largest differences $(p<0.01)$ between the $\mathrm{AB}$ and $\mathrm{CO}$ cyclones existed northeast of the surface low, a direct result of the stronger central CVA maximum in the $\mathrm{CO}$ cyclone and the lesser gradient of $\mathrm{CVA}$ in the $\mathrm{AB}$ cyclone in this region. In comparing the $\mathrm{AB}$ and $\mathrm{EC}$ cyclones, two small regions of significant difference $(p=0.008)$ were found south of the surface low and northeast of the surface low. It is likely that the eastward-displaced center of CVA in the EC cyclone affected the gradients of vorticity advection in this field, causing the region of differences northeast of the low. Southwest of the surface low, the two tracks showed larger differences in the AVA entering into the cyclone with time. Little to no AVA appeared in the AB cyclone; however, EC cyclones displayed much broader regions of weak AVA, and this result is seen as significant in the permutation tests. The final comparison between the $\mathrm{CO}$ and $\mathrm{EC}$ cyclones revealed largely similar magnitudes in both fields $(p>0.1)$. The faster northeastward translation of the CVA maximum in the EC cyclone led to some areas of significant difference in the northeast quadrant of the mean fields, supported by $p$ values as low as 0.002 .
The slightly farther displaced region of maximum AVA in the EC cyclone displayed another small region of significant difference south-southeast of the low as well $(p<0.05)$.

\section{c. $\boldsymbol{Q}$-vector divergence-convergence}

The $\mathbf{Q}$-vector divergence field is used to diagnose vertical motion in synoptic storms across North America (Hoskins et al. 1978; Sanders and Hoskins 1990). Features consistent with the differential geostrophic vorticity advection fields at midlevels were observed within the 500-hPa $\mathbf{Q}$-vector divergence fields in all three tracks. The AB cyclones (Fig. 8) had maxima in $\mathbf{Q}$-vector convergence (rising motion) centered north and west of the surface low through $t_{0}$ (Fig. 8c). Forcing associated with the $\mathbf{Q}$-vector field maintained a position north of the surface low throughout the entire time in the storm's temporal sequence, but magnitudes weakened with the weakening midlevel cyclone. The position was displaced slightly northward, from the maximum CVA associated with $\mathrm{AB}$ cyclones through all times, but the general westward tilt with height was evident as the maxima in $\mathbf{Q}$-vector convergence remain 


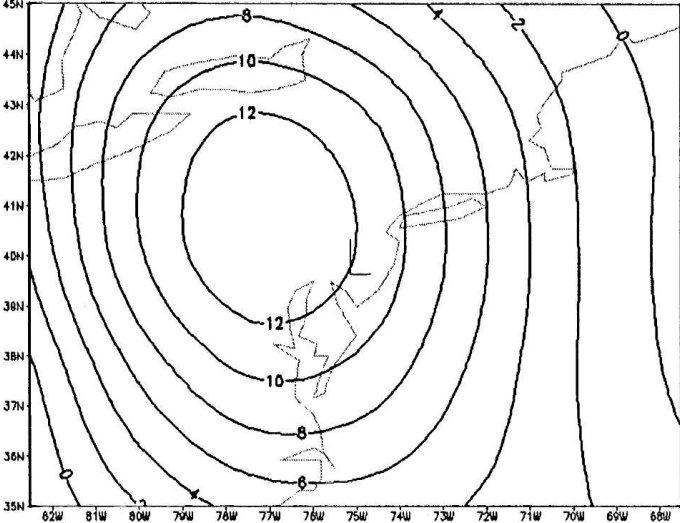

(a)

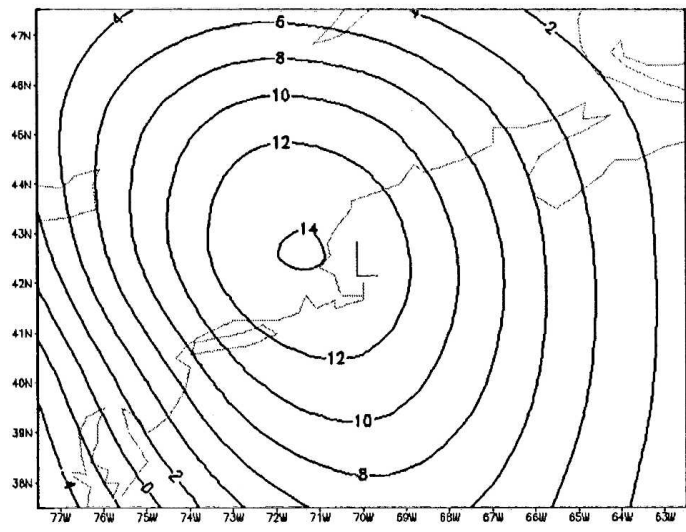

(b)

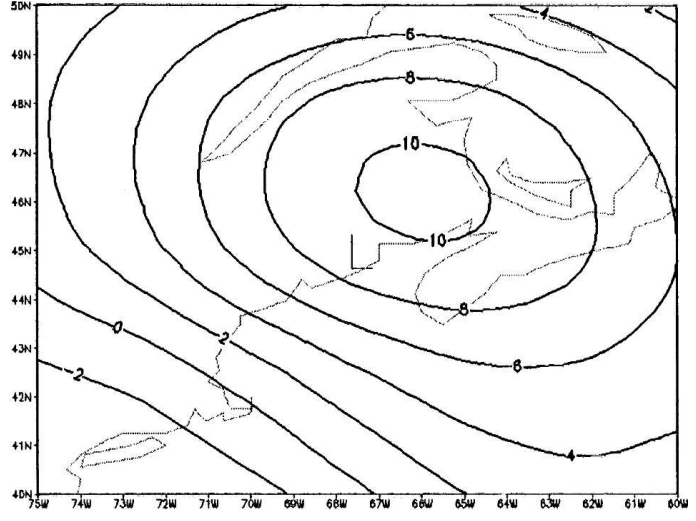

(c)

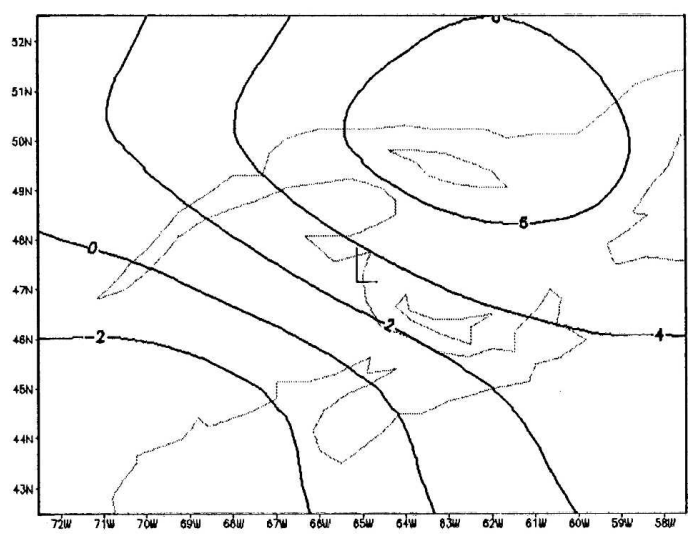

(d)

FIG. 7. Same as in Fig. 5, but for the EC cyclones.

displaced north-northwest of the surface low. Weak areas of $\mathbf{Q}$-vector divergence appeared southwest of the surface low as well, evidence of the approaching midlevel anticyclone and consistent with the AVA field at this level. Unique to the $\mathbf{Q}$-vector convergence field was the continued increase in magnitude of $\mathbf{Q}$-vector convergence through $t_{0}$, which was in agreement with the CVA magnitudes through this time for the $\mathrm{AB}$ cyclone. The spatial similarities in the $\mathbf{Q}$-vector convergence fields and the CVA fields in the $\mathrm{AB}$ cyclones imply a significant portion of the vertical motion associated with the $\mathrm{AB}$ cyclones at midlevels is a result of differential CVA.

The CO cyclones (Fig. 9) exhibited properties similar to the $\mathrm{AB}$ cyclones in the $\mathbf{Q}$-vector $500-\mathrm{hPa}$ divergence field. A maximum of $\mathbf{Q}$-vector convergence appeared northwest of the surface low and maintained this position through $t_{0}$ (Fig. 9c), while the magnitude strengthened slightly (about $20 \%-25 \%$ ). This spatial orientation corresponded with the differential geostrophic absolute vorticity advection fields through $t_{-12}$ (Fig. 9b), as the maximum CVA maintained a position west of the surface low. This result reinforced the presence of the westward tilt with the height of the midlevel cyclone in relation to the surface low pressure center. However, CVA decreased in the CO cyclone by $t_{0}$, while the magnitude of $\mathbf{Q}$-vector convergence continued to increase throughout that time period. This suggested additional quasigeostrophic forcing was present in the $\mathrm{CO}$ cyclone at $t_{0}$ at midlevels, which was determined to be $500-\mathrm{hPa}$ temperature advection (not shown). By $t_{+12}$ (Fig. 9d), the magnitude of maximum $\mathbf{Q}$-vector convergence had weakened considerably (about $50 \%$ ), a response to the declining cyclone. The $\mathbf{Q}$-vector divergence appeared southwest of the surface low in the mean $\mathrm{CO}$ cyclone as well, corresponding well with the region of AVA appearing through the first three time intervals in the $\mathrm{CO}$ track. These results were consistent with those of Barnes and Colman (1994), who produced a nested grid model (NGM) surface low pressure forecast, based on the $\mathbf{Q}$-vector field and potential vorticity fields. In the Barnes and Coleman study, a maximum of $\mathbf{Q}$-vector convergence and rising motion was seen consistently northwest of the surface low. 


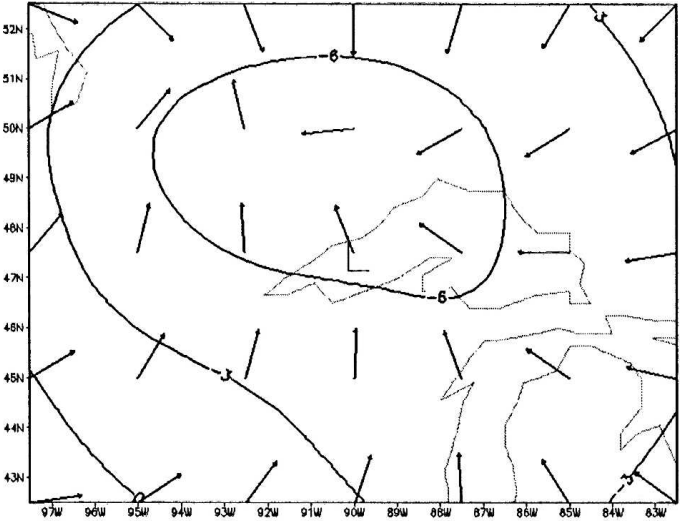

(a)

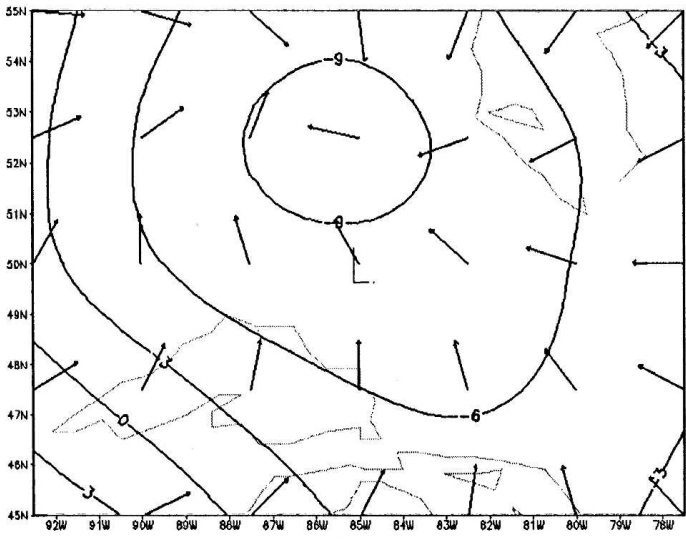

(b)

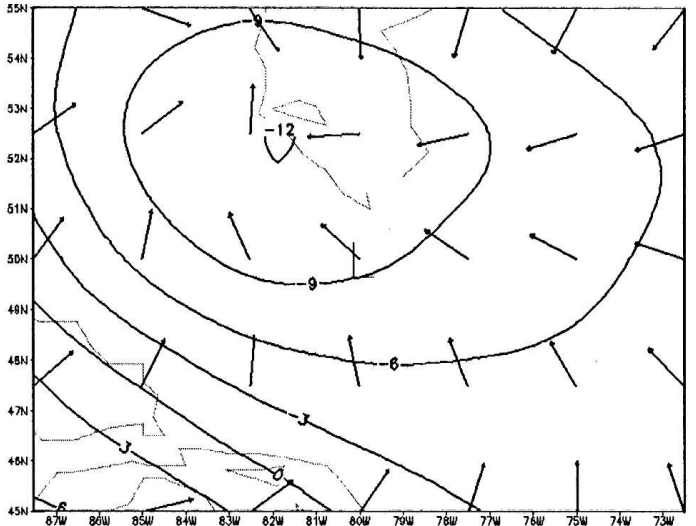

(c)

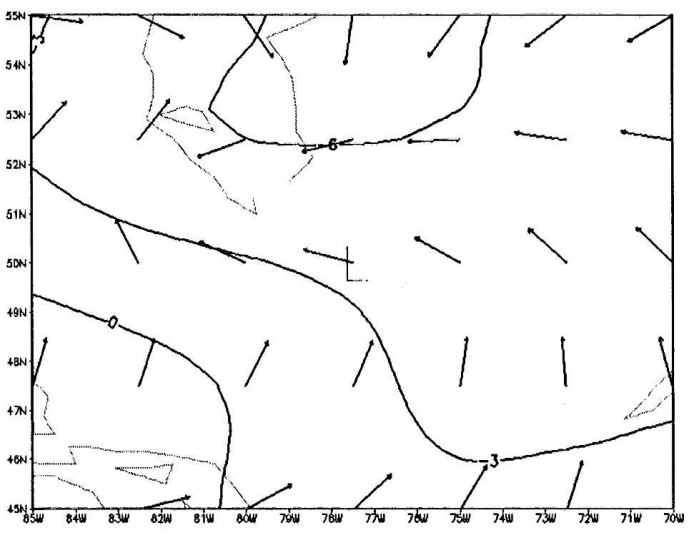

(d)

FIG. 8. The $\mathbf{Q}$-vector divergence at $500 \mathrm{hPa}$ for the $\mathrm{AB}$ cyclones: (a) $t_{-24}$, (b) $t_{-12}$, (c) $t_{0}$, and (d) $t_{+12}$. The solid contours represent $\mathbf{Q}$-vector divergence in $10^{-16} \mathrm{~Pa} \mathrm{~m}^{-2} \mathrm{~s}^{-1}$ and vectors are plotted mean $\mathbf{Q}$ vectors.

For the EC cyclone (Fig. 10), the maximum Q-vector convergence region maintained a position northwest of the surface low through $t_{0}$ (Fig. 10c), in agreement with the previous two tracks. The $\mathbf{Q}$-vector convergence increased in magnitude slightly by $t_{-12}$ (Fig. 10b), but a sharp decrease $(20 \%-25 \%)$ in magnitude occurred by $t_{0}$ in the EC cyclone. This was consistent with the aforementioned decrease in CVA magnitude of the EC cyclone through this same time in the storm's temporal sequence. This result suggested that CVA is a major forcing mechanism at midlevels in the EC storm, although further analysis of the thermal advection field at this level would be required to determine the extent of this point. By $t_{+12}$ (Fig. 10d), the magnitude of $\mathbf{Q}$-vector convergence had diminished by almost $50 \%$, implying an occluding cyclone by this time, which was supported by weaker CVA and temperature advection magnitudes as well. Evidence of the westward tilt with height is seen in the EC results, as fields in the EC cyclone were consistent with those in the previous two tracks in terms of the location of maximum $\mathbf{Q}$-vector conver- gence. Additionally, Q-vector divergence appeared southwest of the surface low in the EC cyclone, consistent with the onset of the midlevel anticyclone. Gyakum (1991) showed for the Queen Elizabeth II storm Q-vector convergence maxima were oriented northwest of the surface low, with time, and spread eastward north of the surface, supporting the results in the present study.

Generally, the correlations (Table 2c) of $\mathbf{Q}$-vector divergence were high between the $\mathrm{AB}$ and $\mathrm{CO}$ cyclones and between the $\mathrm{CO}$ and $\mathrm{EC}$ cyclones. The $\mathrm{AB}$ and $\mathrm{EC}$ cyclones had considerably lower correlations at $t_{-24}$ and $t_{+12}(0.79)$, which are attributed to the farther displaced northwestward $\mathbf{Q}$-vector convergence maxima in the $\mathrm{AB}$ cyclone and the dispersion of $\mathbf{Q}$-vector convergence in the $\mathrm{AB}$ cyclone by $t_{+12}$. All three tracks had the lowest correlations at $t_{+12}$, but correlations for $\mathrm{AB}$ to $\mathrm{CO}$ and $\mathrm{CO}$ to $\mathrm{EC}$ were near 0.9. The high correlations at the two most dynamic times in the storm tracks are manifestations of the similarly oriented $\mathbf{Q}$-vector convergence maxima northwest of the surface low and 


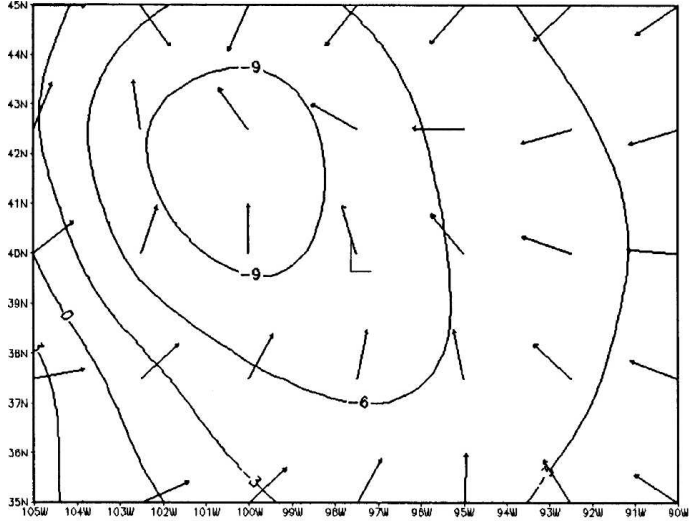

(a)

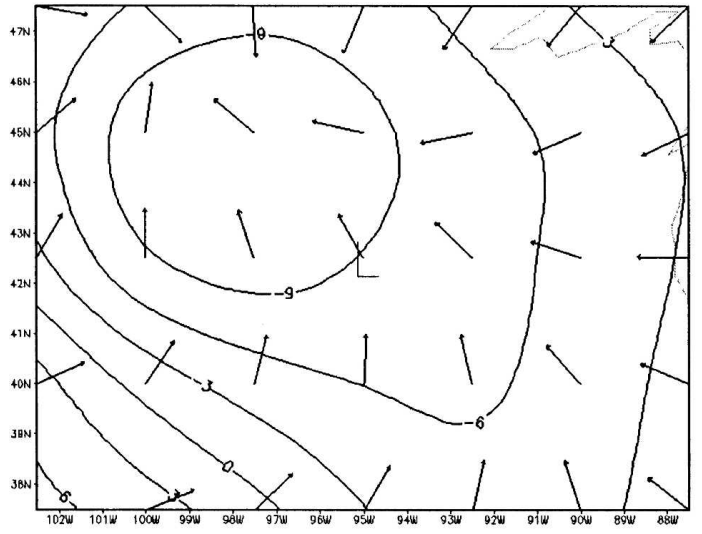

(b)

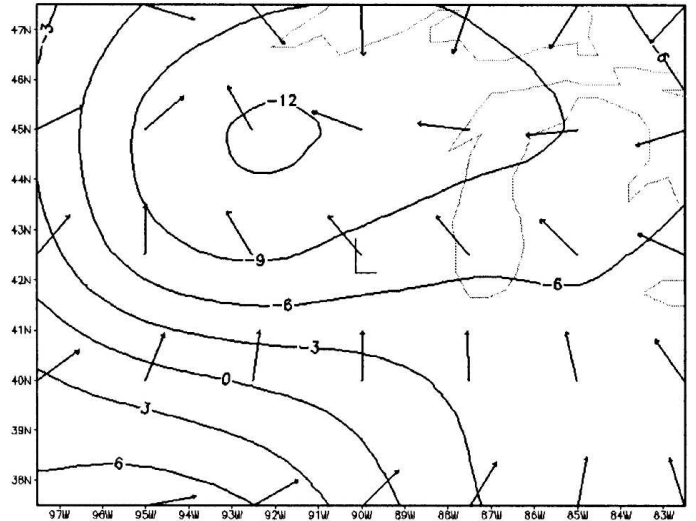

(c)

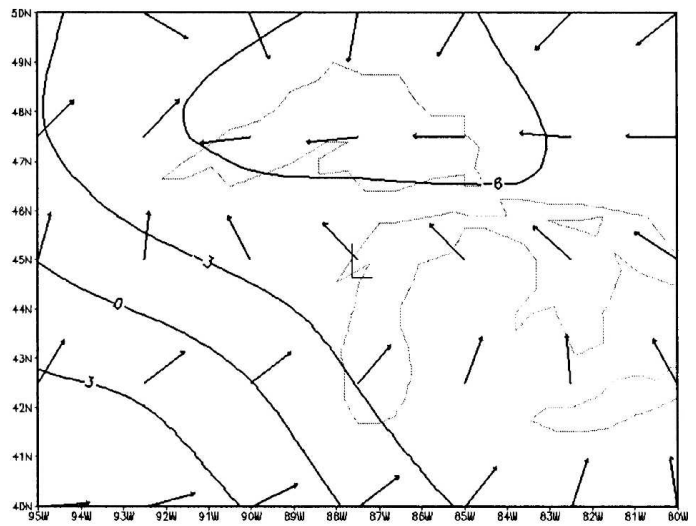

(d)

FIG. 9. Same as in Fig. 5, but for the CO cyclones.

indicate the westward tilt of the cyclone. Results from the permutation tests $\left(t_{0}\right)$ exposed regions of significant magnitude difference south of the surface low ( $p$ value $<0.01$ for eight gridpoints) for the $\mathrm{AB}$ and $\mathrm{CO}$ cyclones. These differences were a result of the larger magnitudes of $\mathbf{Q}$-vector divergence southwest of the low during this time. The $p$ values associated with the permutation tests between the $\mathrm{AB}$ and $\mathrm{EC}$ cyclones were generally less than 0.01 as well, with the main differences noted south of the surface low. The cause of these dissimilarities was the same as for differences between $\mathrm{AB}$ and $\mathrm{CO}$. The final set of permutation tests between the $\mathrm{CO}$ and EC cyclones revealed an overall similar pattern in terms of magnitude, with all $p$ values larger than 0.05 . This result, combined with the previous two, implied that the $\mathrm{AB}$ cyclones have a unique dynamic feature south of the central low pressure that does not appear in the other two cyclones, a noteworthy finding. This difference was manifest in the mean fields as a general east-west-oriented $\mathbf{Q}$-vector divergence field is seen in the $\mathrm{CO}$ and $\mathrm{EC}$ cyclones but not in the $\mathrm{AB}$ cyclones. It is thought that this difference is a result of the unique $\mathbf{Q}$-vector orientations associated with $\mathrm{AB}$ cyclones versus those in the other two tracks and helps to differentiate the $\mathrm{AB}$ cyclones.

\section{d. Midlevel stability}

Stability was computed for two layers, $700-500 \mathrm{hPa}$ (midlevel) and 850-700 hPa (low level). The AB cyclones (Fig. 11) indicated a gradual increase of midlevel stability for the entire profile from $t_{-24}$ (Fig. 11a) to $t_{+12}$ (Fig. 11d). A region of maximum midlevel instability was present on a consistent basis south of the surface low for all times in the $\mathrm{AB}$ cyclone. This concurs with the expected orientation of the stability fields in the Northern Hemisphere (stability increasing with increasing latitude). However, a closed maximum region of instability south of the low suggested rising motion and precipitation in that location, the expected warm sector of the low pressure system. These results corresponded well with those presented in Schultz and Doswell (2000), who suggest a maximum of warm air advection southeast of the low, implying warmer air south of the low. Variability in the stability field at midlevels was low, reflected by broad gradients of midlevel stability in the mean fields. Taken collectively, these findings sug- 


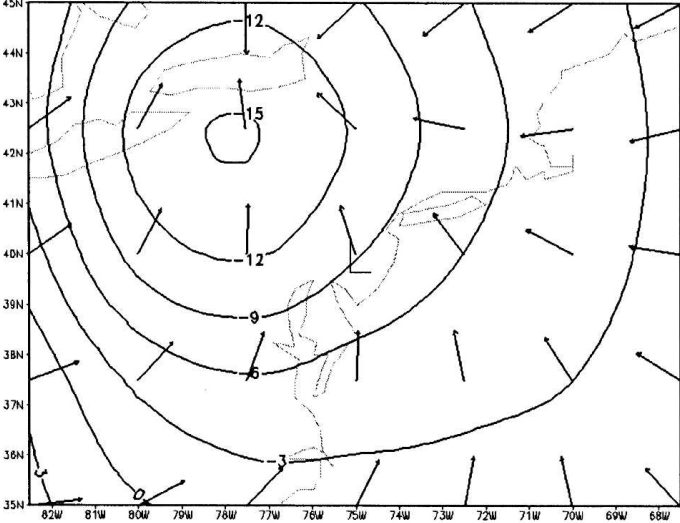

(a)

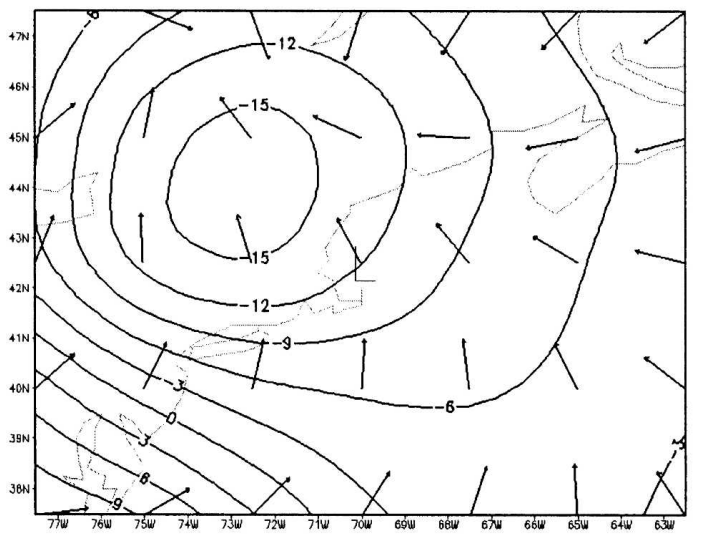

(b)

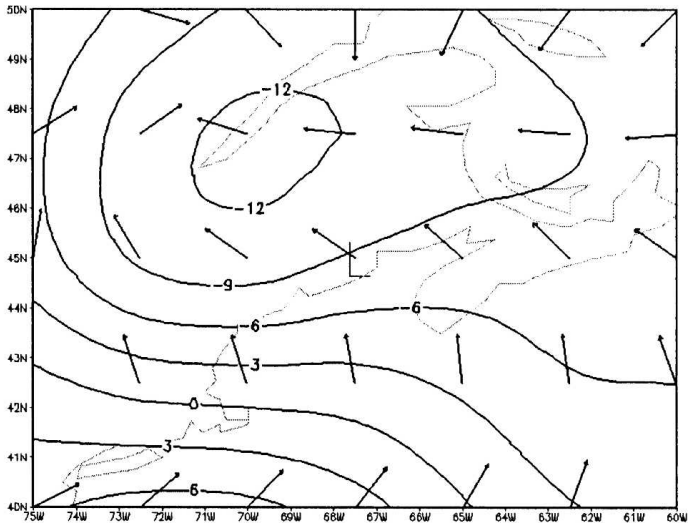

(c)

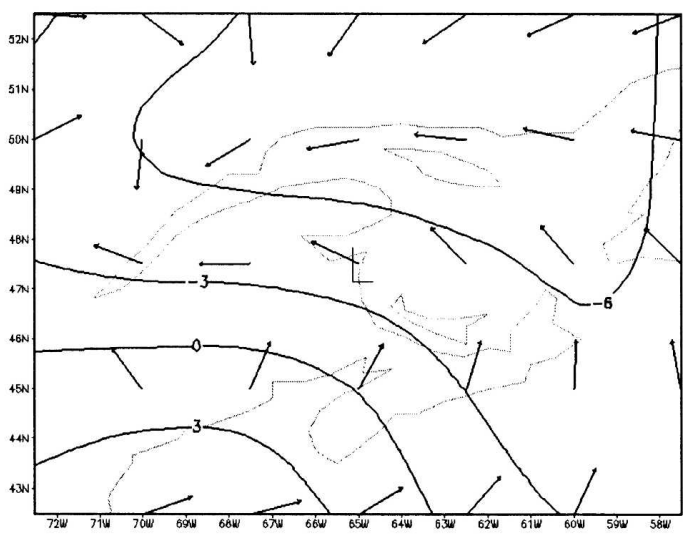

(d)

FIG. 10. Same as in Fig. 5, but for the EC cyclones.

gested that midlevels are well suited for quasigeostrophic analysis, since quasigeostrophic theory requires constant horizontal static stability.

For the CO cyclones (Fig. 12), the maximum of midlevel stability remained slightly south and east of the surface low for all times in the track. As with the $\mathrm{AB}$ cyclones, the $\mathrm{CO}$ cyclones became more stable at each time step. Furthermore, the maximum instability shifted eastward with time, a result expected as a consequence of the eastward shift of the warm sector of the mean $\mathrm{CO}$ cyclone as the cyclone becomes more wrapped and eventually occludes. Marshment and Horn (1986) showed a region of maximum instability southeast of the surface low at the time of deepest storm depth for a sample of 39 cases. Such results were consistent with those presented herein, despite Marshment and Horn using the Showalter index for their analysis of stability. As with the $\mathrm{AB}$ cyclones, the gradient of stability was low at all times in the mean $\mathrm{CO}$ cyclone, supporting the validity of quasigeostrophic theory for midlevels in the $\mathrm{CO}$ cyclones.

In the EC cyclone, at midlevels (Fig. 13), the maxima of instability remained centered to slightly east of the surface low through all times in the storm track. Unlike the previous two tracks, the EC cyclones maintained a moderately constant magnitude of stability (and instability) throughout their evolution, although the instability region shifts eastward with time, as with the previous two tracks. Numerous temperature advection studies on the EC cyclones (e.g., Gyakum 1983, 1991; Gyakum et al. 1992) suggested a maximum of warm air advection shifting eastward with time, which implies an eastward shift of the warm sector relative to the center of the low. The midlevel stability analyses presented herein supported those previous results, quantifying previous results for the EC cyclone. Once again, the gradient of midlevel stability was low for all times in the EC cyclone's temporal sequence, which permits the use of quasigeostrophic theory at midlevels.

An intercomparison of the three tracks revealed that the $\mathrm{AB}$ cyclones were the most dissimilar when evaluated against the other two tracks. The AB cyclones had the strongest instability at midlevels at all times, an unexpected result since warmer air and larger instabil- 


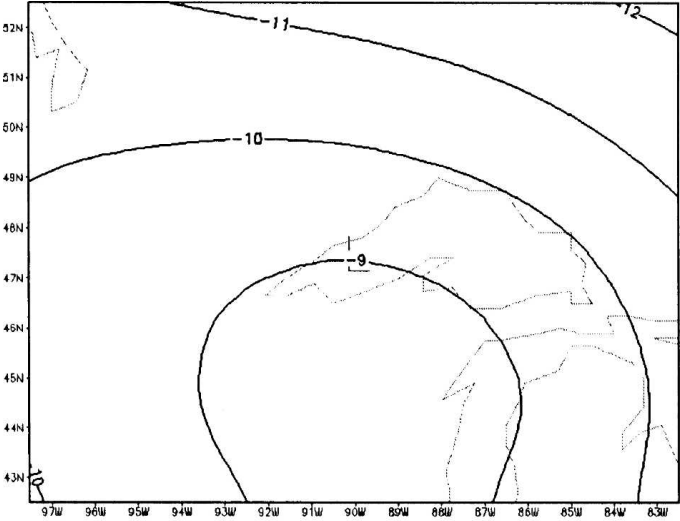

(a)

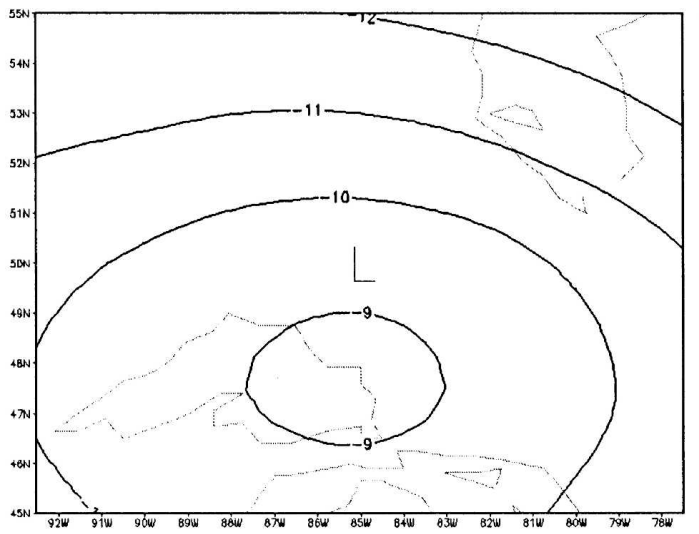

(b)

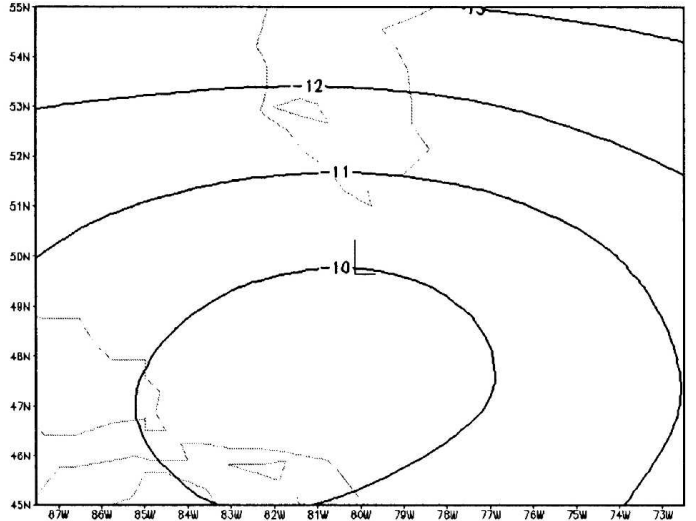

(c)

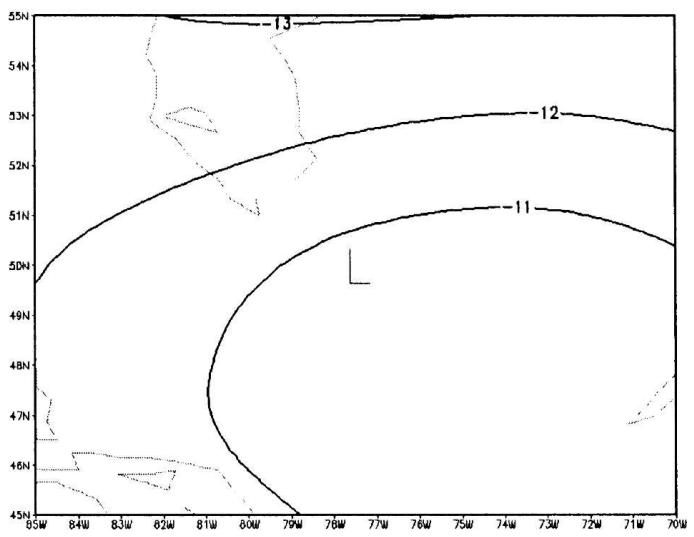

(d)

FIG. 11. Stability for the 700-500-hPa layer. Numbers closer to zero represent a more unstable region. Stability is represented here in $\mathrm{K}$. (a) $t_{-24}$, (b) $t_{-12}$, (c) $t_{0}$, and (d) $t_{+12}$. These figures are valid for the AB systems.

ity existed at lower latitudes. This new result suggests that combining the $\mathrm{AB}$ and $\mathrm{CO}$ cyclones for diagnostic analysis may not be an appropriate methodology. The correlations (Table 2d) between the $\mathrm{AB}$ cyclones and both the $\mathrm{CO}$ and $\mathrm{EC}$ cyclones were very low compared to the correlations between the $\mathrm{CO}$ and $\mathrm{EC}$ cyclones, supporting these visual differences between the AB cyclones and the other two tracks. The lowest correlations (both 0.61 ) occurred between the $\mathrm{AB}$ and $\mathrm{CO}$ cyclones at $t_{-24}$ and $t_{+12}$, as spatial locations of maximum instability in the $\mathrm{AB}$ cyclone were farther west and south than in the $\mathrm{CO}$ cyclone. In the $\mathrm{EC}$ cyclone, the lowest correlation (0.69) occurred at $t_{0}$, as the EC cyclone evolved more quickly and the maximum of instability shifted farther eastward by $t_{0}$. These results suggested that regions of similar geography $(\mathrm{AB}$ and $\mathrm{CO})$ do not have similar stability profiles at midlevels. However, one should be careful interpreting these correlations as the magnitudes of stability do not vary much throughout the field and small differences led to low correlations due to this lack of variability in the track. The permutation tests between the tracks revealed that the $\mathrm{AB}$ and $\mathrm{CO}$ cyclones are statistically similar in the magnitude of stability at all grid points, with only 2 of the 35 grid points having a $p$ value lower than 0.05 . Taken collectively, this confirms that stability profiles in the $\mathrm{CO}$ and the $\mathrm{AB}$ cyclones were similar in magnitude, although their spatial orientation remained different. When comparing the $\mathrm{AB}$ and $\mathrm{EC}$ cyclones, significant differences in the fields existed across the western third of the plot, where numerous grid points show highly significant differences $(p<0.01)$. Due east of the surface low, another region exhibited large differences in stability $(p<0.01)$. The mean EC storm was more stable than the mean $\mathrm{AB}$ cyclone causing these significant differences. A comparison of the $\mathrm{CO}$ and $\mathrm{EC}$ fields revealed only one small region northeast of the surface low that showed similarities, while the remainder of the field was highly different $(p<0.01$ for $75 \%$ of the grid points). Again, these differences were a result of the more stable EC cyclone in comparison with the $\mathrm{CO}$ cyclone. 


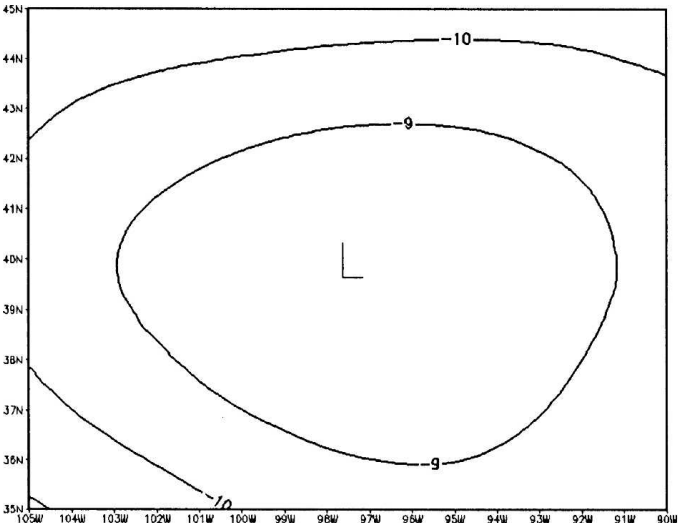

(a)

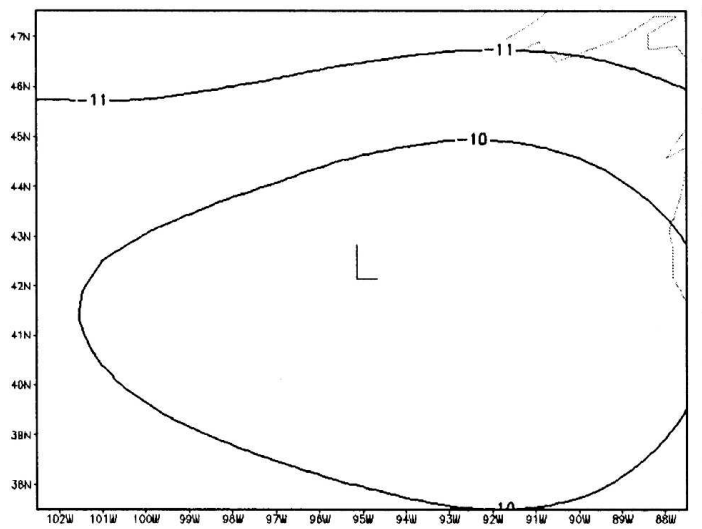

(b)

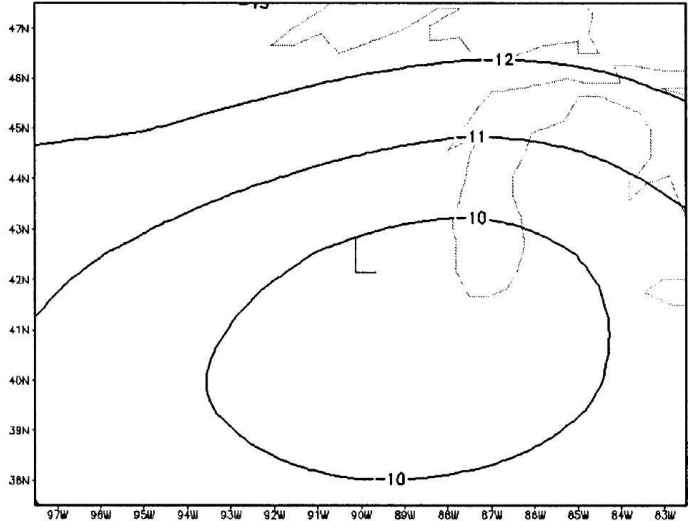

(c)

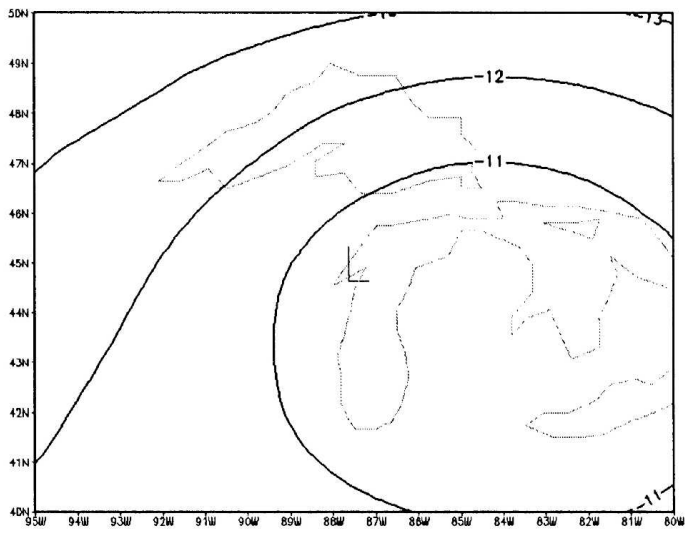

(d)

FIG. 12. Same as in Fig. 11, but for the CO cyclones.

\section{e. Low-level stability}

A more dynamic stability field was presented in the AB cyclone at low levels (Fig. 14) versus midlevels. Examination of the temporal sequence indicated that a maximum of instability began southwest of the surface low and shifted eastward terminating southeast of the surface low by $t_{+12}$. This result implied an eastwardshifting warm sector of the $\mathrm{AB}$ cyclone, consistent with previous results for midlevels. The magnitude of instability decreased slightly $(\sim 20 \%)$ with time. Maximum stability maintained a position north of the surface low through $t_{0}$, although evidence of the eastward-shifting cold front was present by $t_{+12}$ as a trough of stability appeared due west of the surface low by that time. Such differences, and slightly tighter gradients of stability present at low levels, suggested that quasigeostrophic theory is not as valid of an assumption at low levels.

In the $\mathrm{CO}$ cyclone (Fig. 15), the region of maximum instability was southwest of the surface low, offset from the midlevel stability maxima for the same cyclone. The $\mathrm{CO}$ cyclone was much more unstable at low levels than the AB cyclone $(20 \%-25 \%)$, and stability increased with time throughout the temporal evolution of the cyclone. By $t_{+12}$, the maximum of instability moved southeast of the surface low, an eastward-shifting profile consistent with the $\mathrm{AB}$ cyclone at low levels. Another result consistent with the $\mathrm{AB}$ cyclone was the presence of a trough of maximum stability west of the surface low by $t_{+12}$, implying that colder air is filtering in behind the eastward-moving cyclone. A slightly tighter low-level stability gradient was present in the $\mathrm{CO}$ cyclone as well, suggesting that quasigeostrophic theory was not as good of an assumption as at the midlevels. Marshment and Horn (1986) provided evidence for an eastward propagation of stability as well, consistent with the results herein.

In the EC cyclone (Fig. 16), the stability profiles at low levels took on a considerably different configuration than the other two tracks. The low-level stability maximum commenced southeast of the surface low and, although it weakened in time, as occurred for all other tracks, it shifted northward. This finding implies that the warm sector was farther east than for the other two tracks. Smith et al. (1988) showed regions of maximum static instability at 900 and $700 \mathrm{hPa}$ consistently 


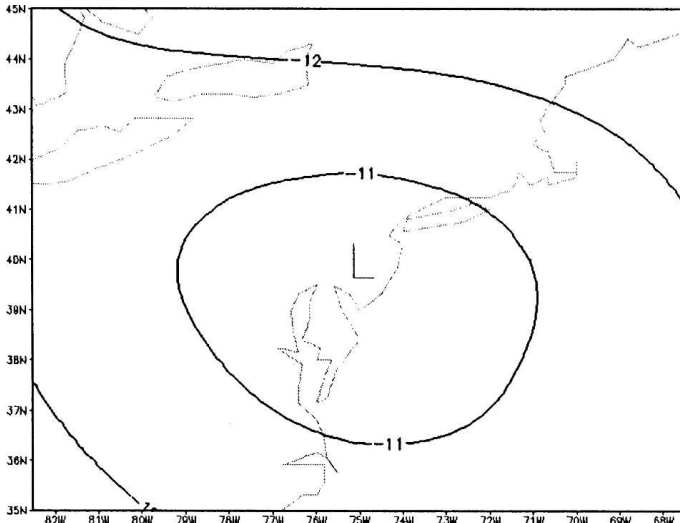

(a)

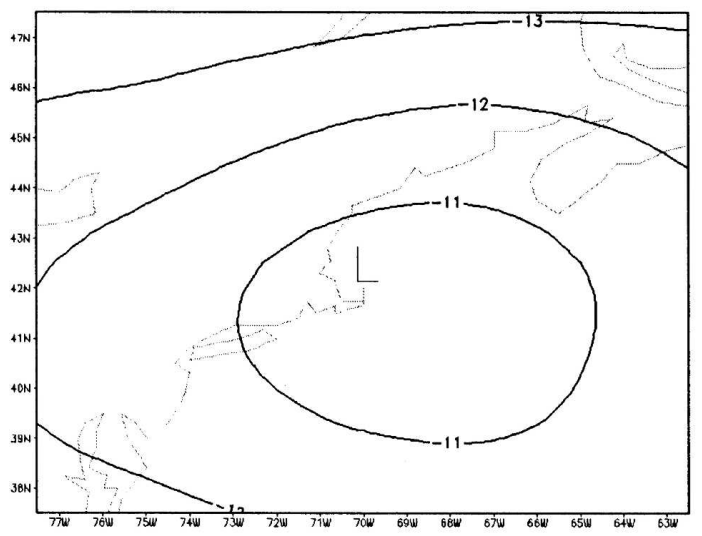

(b)

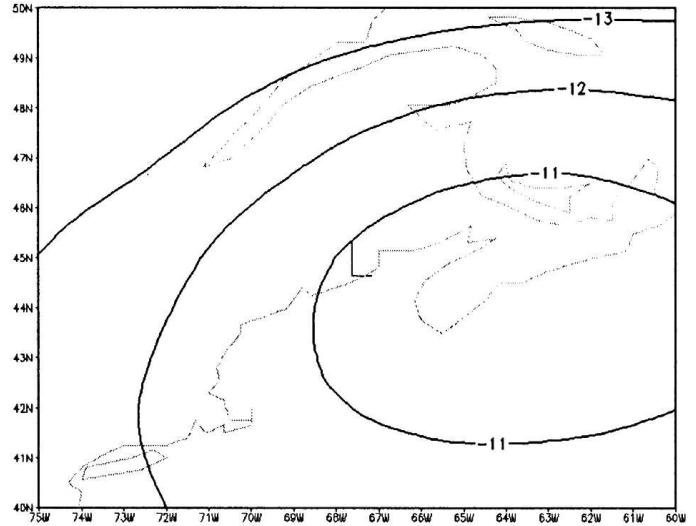

(c)

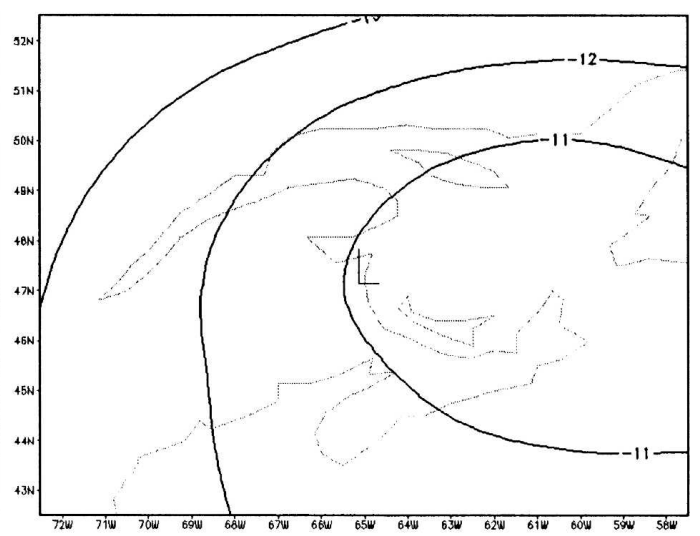

(d)

FIG. 13. Same as in Fig. 11, but for the EC cyclones.

east-northeast of the surface low, which supports the eastward placed instability in the present results. One figure in Smith et al. (1988, their Fig. 4) showed increasing stability in time near the time of lowest surface pressure, supporting the results presented herein. The trough of high stability west of the low appeared by $t_{0}$ in the EC cyclone, although this region was not well defined at any point in the track. Here again, the gradients of stability were slightly tighter than at midlevels, implying quasigeostrophic theory is not a fully valid assumption at low levels.

Analysis of the correlations between the tracks (Table 2e) revealed high values between the $\mathrm{AB}$ and $\mathrm{CO}$ cyclones, consistent with the previous discussion on the $\mathrm{CO}$ cyclones. The significant differences in the EC cyclones were manifest as low correlations between the $\mathrm{EC}$ cyclones and both the $\mathrm{CO}$ and $\mathrm{AB}$ cyclones. Correlations as low as 0.5 were present for $t_{-24}, t_{-12}$, and $t_{+12}$ for both the $\mathrm{CO}$ and $\mathrm{AB}$ cyclones in comparison with the EC cyclones, a result confirmed by visual analysis of the fields. At $t_{0}$, both the $\mathrm{CO}$ and $\mathrm{AB}$ cyclones correlated more strongly with the EC cyclones
(0.77), a consequence of the EC mean cyclone exhibiting the weak trough of maximum stability west of the low at this time and the maximum instability southeast of all three storm types by this time in the evolution. Clearly, the low-level stability fields in the EC cyclones were unique in comparison with the other two tracks. The permutation tests performed on these fields revealed large differences between the EC cyclones and the other two tracks, while $\mathrm{AB}$ and $\mathrm{CO}$ were highly similar ( $p>0.05$ for all but four grid points). Comparing $\mathrm{AB}$ and $\mathrm{EC}$, large differences in magnitude $(p<$ 0.01 ) were revealed southwest and south of the surface low, which are the regions of largest instability in the $\mathrm{AB}$ cyclone. As with midlevels, the $\mathrm{AB}$ cyclones were more unstable than the EC cyclones, and these results appeared as the large differences in magnitudes between the fields. The $\mathrm{CO}$ and EC cyclones had magnitudes similar to $\mathrm{AB}$ and $\mathrm{EC}$, with the most unstable cyclone (i.e., the $\mathrm{CO}$ cyclone) leading to large magnitude differences and large regions of significant difference between the fields $(p<0.01$ for about 20 grid points south and west of the surface low). The permu- 


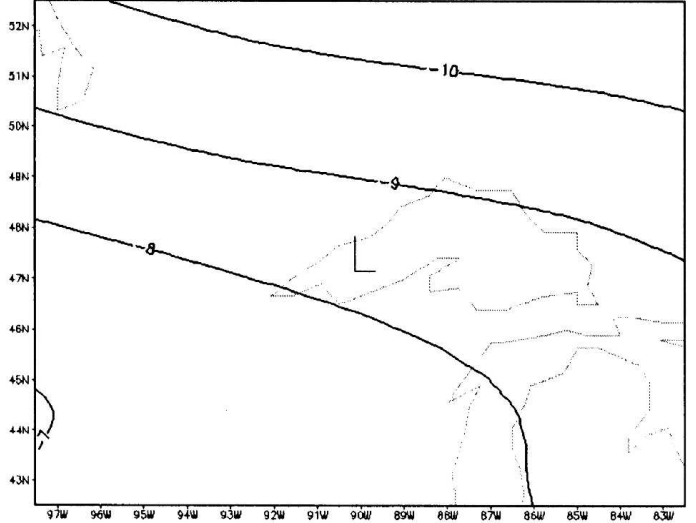

(a)

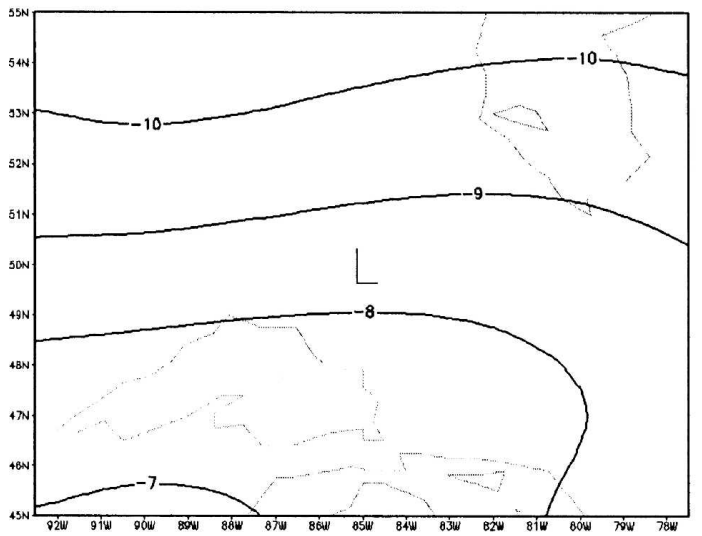

(b)

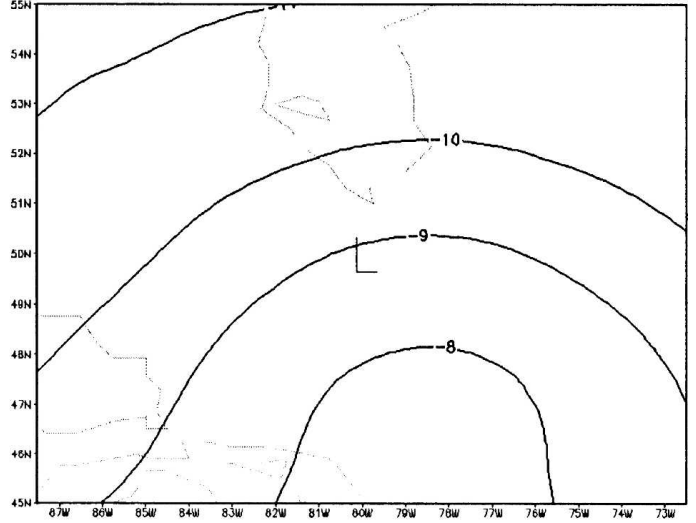

(c)

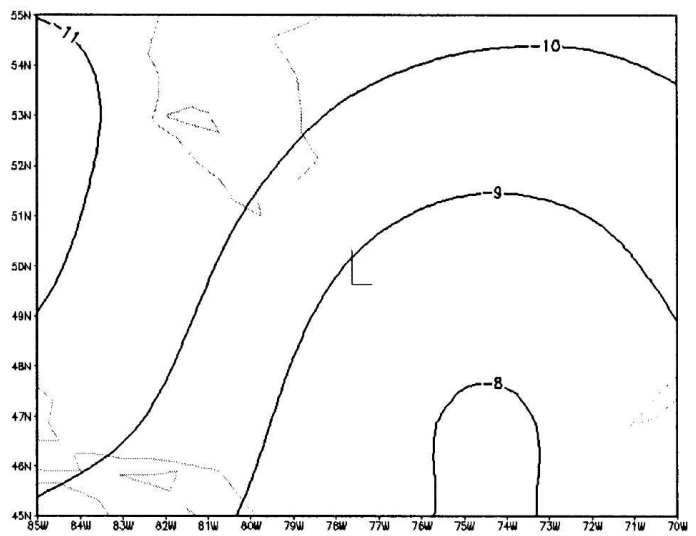

(d)

FIG. 14. Stability for the $850-700-h P a$ layer. Numbers closer to zero represent a more unstable region. Stability is represented here in $\mathrm{K}$. (a) $t_{-24}$, (b) $t_{-12}$, (c) $t_{0}$, and (d) $t_{+12}$. These figures are valid for the AB systems.

tation tests and correlations supported similar stability profiles of the $\mathrm{AB}$ and $\mathrm{CO}$ cyclones, whereas the EC cyclones were found to be more stable, having different orientations in their isopleths.

\section{f. Mean layer specific humidity}

The AB moisture fields (Fig. 17) illustrated regions of maximum moisture southeast of the surface low, juxtaposed with the southerly flow from the wind patterns of the surface low. The maximum of moisture decreased in magnitude with time, with little change in position noted until the final time in the track. At $t_{+12}$, the moisture axis shifted to the extreme southeastern corner of the domain, progressing with the eastwardmoving cold front. The magnitude of moisture decreased by almost $25 \%$ by the final time in the AB cyclone, likely a result of colder, dry air being advected into the cyclone behind the cold front combined with precipitation eroding the moisture content of the atmosphere in this region. The driest air was present north of the surface low, consistent with the gradient of North
American dewpoints presented in Dodd (1965). However, the loss of moisture with the southeastward motion of the AB cyclone disagrees with Dodd's (1965) increase of moisture with decreasing latitude.

In the $\mathrm{CO}$ cyclone (Fig. 18), the moisture axis was present southeast of the surface low, corresponding directly to the region of southerly flow associated with the cyclone at low levels. The magnitude of moisture was much higher in the $\mathrm{CO}$ cyclone than for the $\mathrm{AB}$ cyclone ( $\sim 33 \%$ more), which can be attributed to these storms advecting more moisture from the Gulf of Mexico into their circulation. As with the AB cyclone, the magnitude of maximum moisture decreased with time, by almost $25 \%$ at $t_{+12}$. Reasons for this moisture decrease appeared to be the same as those proposed for the $\mathrm{AB}$ cyclone (precipitation and advection of cold, dry air into the cyclone). Dodd (1965) found a climatological increase of dewpoint with decreasing latitude, and such an argument is consistent with the results presented herein. One unusual feature of the $\mathrm{CO}$ cyclone was a small variation in the contour field westsouthwest of the surface low. This anomaly was most 


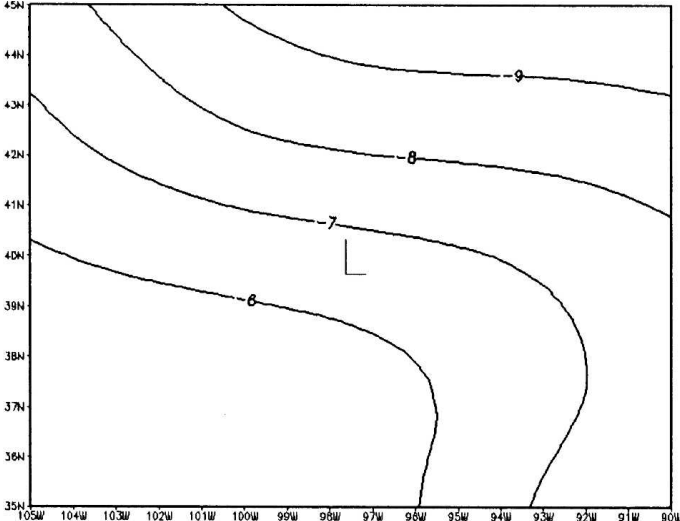

(a)

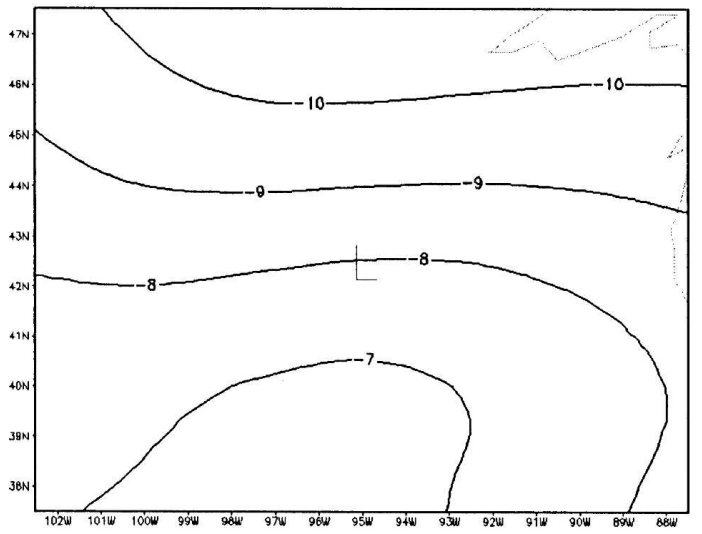

(b)

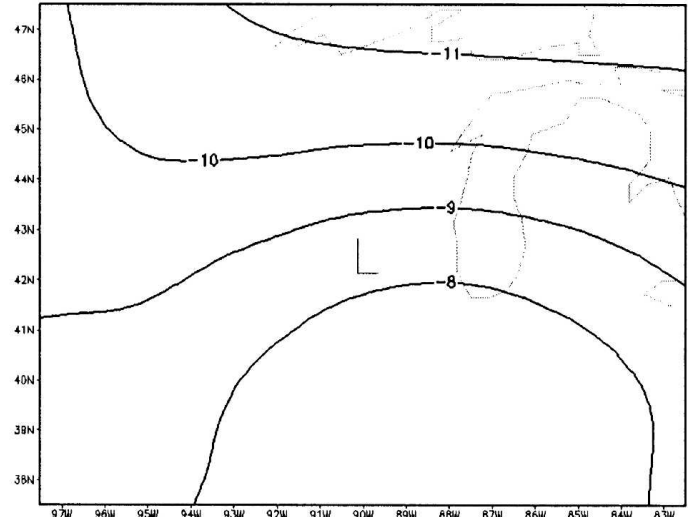

(c)

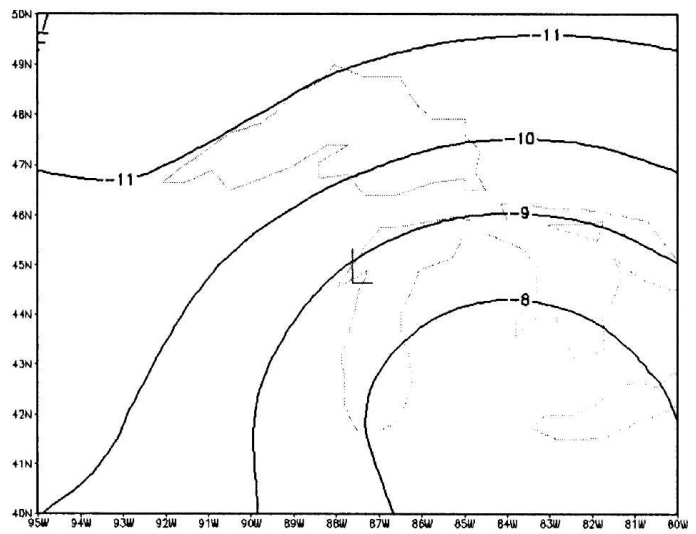

(d)

FIG. 15. Same as in Fig. 14, but for the CO cyclones.

prevalent at $t_{-24}$ and corresponds, in terms of orientation, to the low-level cold front. Additionally, this anomaly appeared in Marshment and Horn's (1986) analysis of the moisture profiles of $\mathrm{CO}$ cyclones.

In the EC cyclone (Fig. 19), although magnitudes of maximum moisture were similar to those in the $\mathrm{CO}$ cyclone, the maximum moisture axis was displaced farther southeast than in the other two tracks. The region of maximum moisture shifted eastward with time, and no evidence of a closed region of maximum moisture was present by $t_{+12}$. This result suggested the faster evolution of the EC cyclone, consistent with the results presented in the stability analysis. In the EC cyclone, a minimum of moisture located northeast of the surface low signified it was drier than that observed in the $\mathrm{CO}$ cyclone, and was closer in magnitude to the $\mathrm{AB}$ cyclone. This result was unexpected since EC cyclones occur at lower latitudes, but suggested that the stronger flow associated with the EC cyclone advects in colder, drier Canadian air behind the cyclone and acts to tighten the moisture gradient across the region. Cold air damming associated with EC cyclones may have aided in the creation of this moisture gradient as well.
In the results of Boyle and Bosart (1986), maximum relative humidity values corresponded well with the strongest flow off the Atlantic (south-southeasterly flow) in the EC cyclones, and those findings supported the results presented herein.

Analysis of the correlations and $p$ values from permutation tests in the three tracks documented the differences in the moisture fields. Correlations between the $\mathrm{AB}$ cyclones and the other two tracks were generally less than 0.85 for all times (Table $2 \mathrm{f}$ ), which was a result of a more westward-located moisture axis and the lack of a moisture gradient in the $\mathrm{AB}$ cyclone. Correlations between the $\mathrm{CO}$ and $\mathrm{EC}$ cyclones were high for all times in the tracks' temporal sequences. Comparing these correlation results with the $p$ values supported the differences in the $\mathrm{AB}$ cyclone, with $p$ values less than 0.01 common for about $60 \%-80 \%$ of the comparisons between $\mathrm{AB}$ and $\mathrm{CO}$ and between $\mathrm{AB}$ and EC. However, an interesting comparison between $\mathrm{CO}$ and $\mathrm{EC}$ revealed similar large magnitude differences, implying that the three tracks can be distinguished based solely on their moisture magnitudes. This result was accounted for by the largest moisture content of the mean $\mathrm{CO}$ 


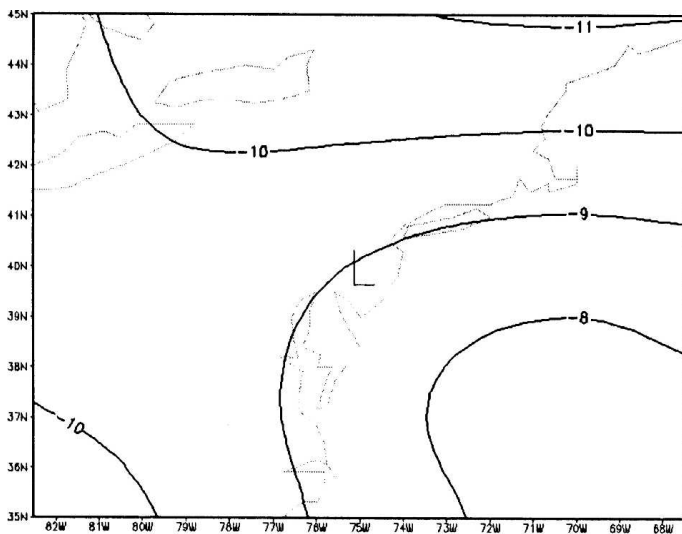

(a)

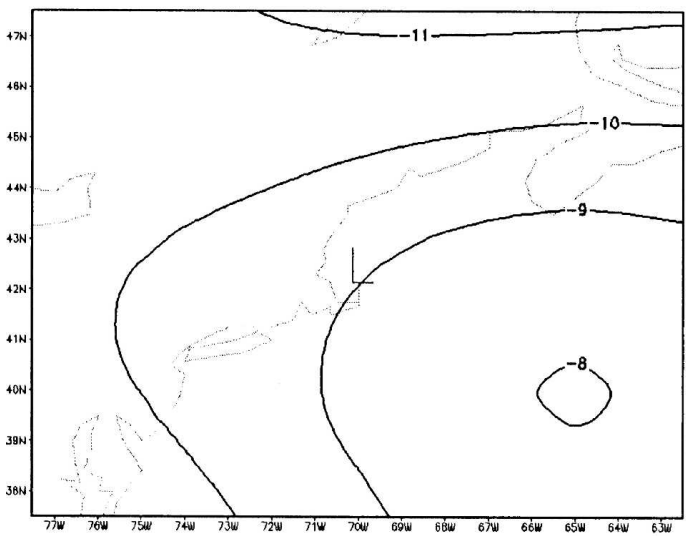

(b)

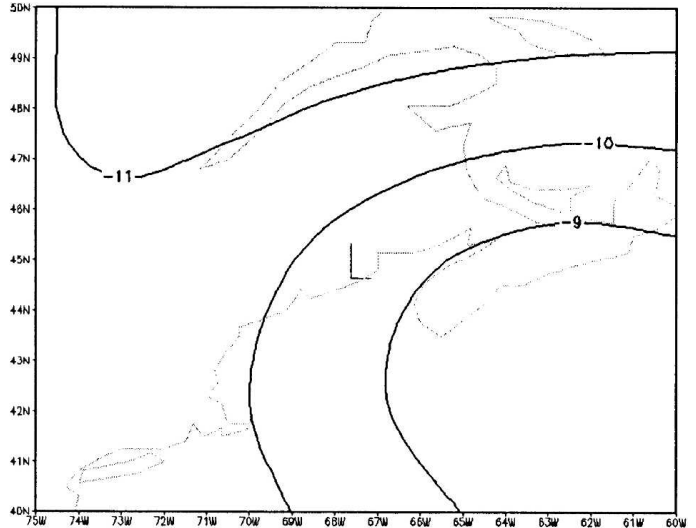

(c)

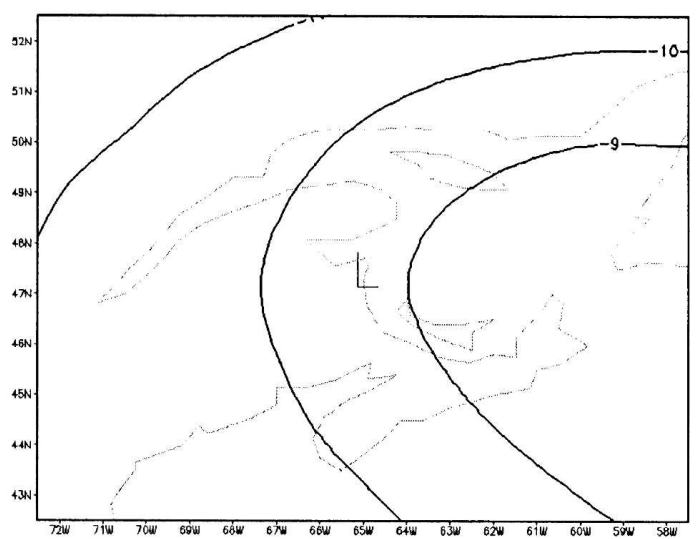

(d)

FIG. 16. Same as in Fig. 14, but for the EC cyclones.

cyclone being higher than seen in the EC cyclone. Despite this, EC cyclones showed the largest gradient in moisture, with the differences between the maximum and minimum moisture in the field about $25 \%$ greater than storms in the other two tracks. Clearly, these cyclones had numerous differences in their low-level moisture profiles.

\section{g. Quartile fields}

To diagnose variability in cyclones in the different tracks, the 25th and 75th percentiles (first and third quartiles) were computed at each of the 35 grid points at $t_{0}$. The maximum and minimum values of these quartiles, as well as the correlations between the quartiles and the mean fields were computed in order to determine the properties of the variability in the cyclones. Table 3 contains all of the above information used in these comparisons.

In analyzing the 850 -hPa temperature advection quartiles (Table 3a), the first point to note is the high correlations between both quartiles and the mean fields $(>0.96)$, implying similar spatial orientations of strong and weak storms in comparison with the mean. However, large differences existed in the magnitudes of the maximum and minimum thermal advection in both quartiles when compared with the mean. Trends of temperature advection for storms in all three tracks were similar. For weak storms, WAA (Table 3a, column 2) was an order of magnitude smaller than for the mean cyclone (Table 3a, column 1), while CAA was an order of magnitude smaller (Table 3a, column 6). An analysis of the advection magnitudes in strong storms revealed similar results, as maximum WAA in strong storms (Table 3a, column 3) was about $65 \%$ stronger than in the mean storm, while CAA in strong storms (Table 3a, column 5) was close to double the strength of the mean cyclone. Therefore, despite strong support for similarly oriented fields, the magnitudes of $850-\mathrm{hPa}$ temperature advection were highly variable, and the associated forcing from this high variation led to a broad spectrum of strength of these cyclones.

The differential absolute geostrophic vorticity advection quartiles (Table $3 \mathrm{~b}$ ) revealed slightly different results than those seen in the 850 -hPa temperature ad- 


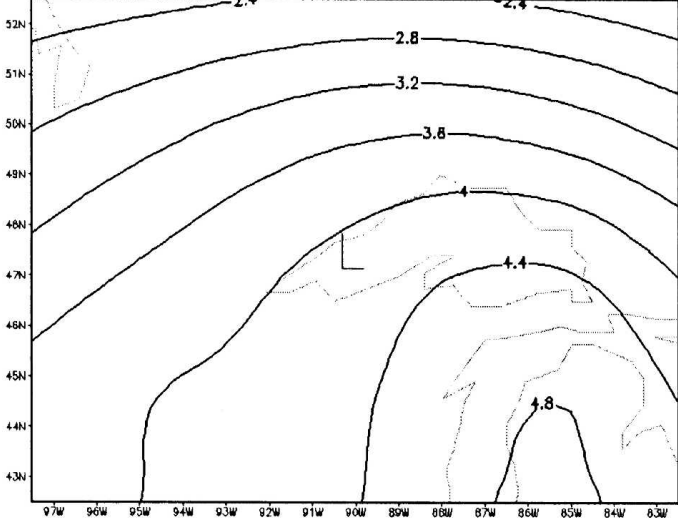

(a)

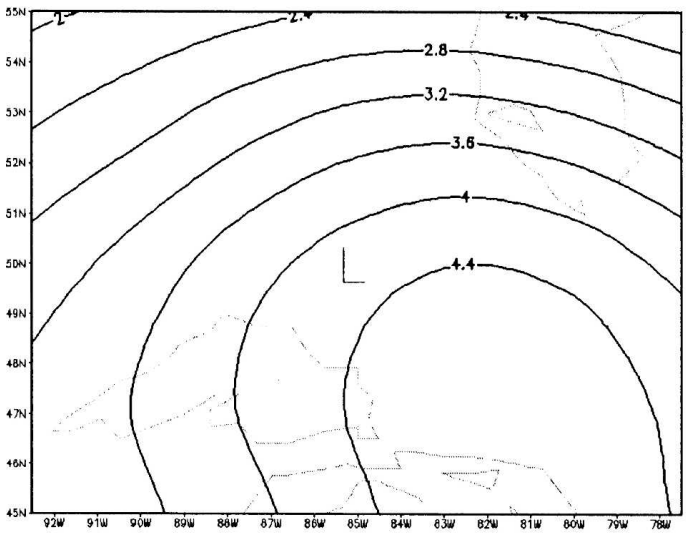

(b)

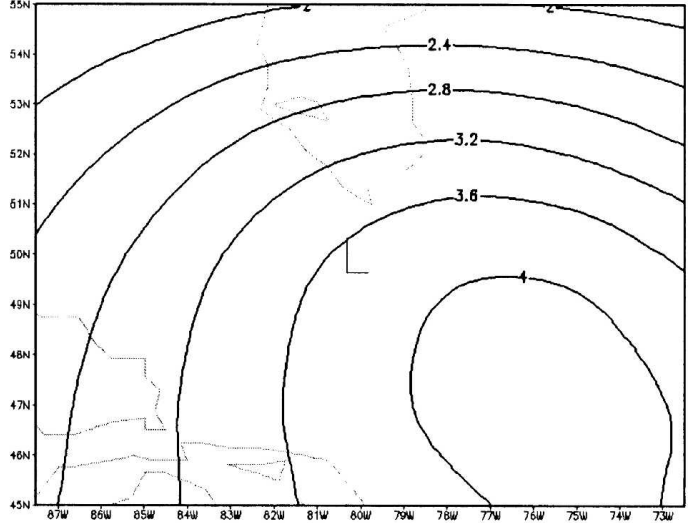

(c)

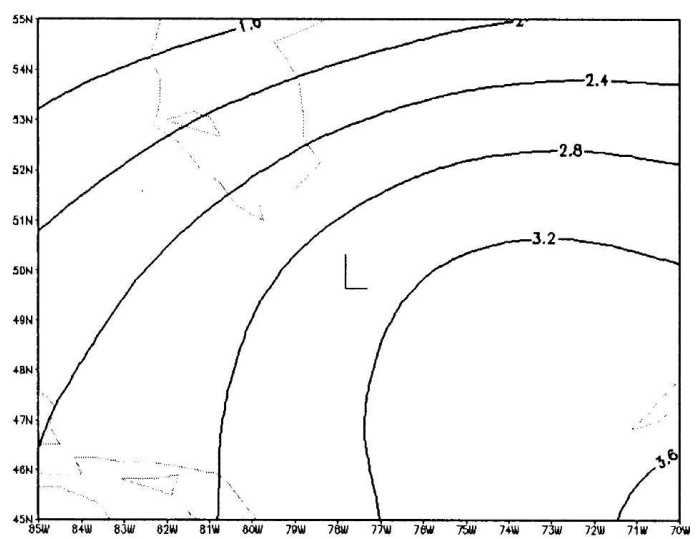

(d)

FIG. 17. Mean specific humidity $\left(\mathrm{g} \mathrm{kg}^{-1}\right.$ ) between 925,850 , and $700 \mathrm{hPa}$ : (a) $t_{-24}$, (b) $t_{-12}$, (c) $t_{0}$, and (d) $t_{+12}$. These figures are valid for the $\mathrm{AB}$ systems.

vection fields. Correlations between the mean and the quartiles in the $\mathrm{AB}$ cyclone were the lowest of all the mean-quartile correlations, although they remain near 0.9 . These differences became more apparent in analysis of the magnitudes in the quartile fields. For the $\mathrm{AB}$ cyclones, weak storms contained CVA (Table 3b, column 2) an order of magnitude weaker than the mean field. This result was consistent with the thermal advection fields, but an interesting point is that the weaker $\mathrm{AB}$ cyclones showed no region of AVA, as the minimum value of vorticity advection in these weak storms (Table 3b, column 6) was only slightly lower than for the maximum vorticity advection in weak storms. This significant difference resulted in the lower correlations between these fields as well. The $\mathrm{CO}$ cyclones had the largest values of CVA and AVA, both in the mean field and for the strong and weak storms. For these storms, the minimum vorticity advection in the weak cyclones was still positive (Table $3 \mathrm{~b}$, column 6), indicating little to no AVA in the weak CO cyclones. For EC cyclones, the weakest magnitudes of vorticity advection of all three tracks were seen. The gradient of vorticity advec- tion in the weak EC cyclones was virtually nonexistent (cf. Table 3b, column 2 and Table 3b, column 6), but the strongest storms still maintained values of vorticity advection similar to those seen in the other two tracks.

For Q-vector divergence at $500 \mathrm{hPa}$ (Table 3c), results were similar to those for the vorticity advection. No $\mathbf{Q}$-vector divergence existed in weak storms in any of the three tracks (Table 3c, columns 2 and 6 are all negative), and the strongest $\mathbf{Q}$-vector convergence (Table 3c, column 6) was roughly $40 \%$ stronger than was seen in the mean field. For strong cyclones, Qvector convergence (Table 3c, column 5) was up to $50 \%$ stronger than the mean field (Table 3c, column 4), while $\mathbf{Q}$-vector divergence (Table 3c, column 3) was an order of magnitude stronger than the mean $\mathbf{Q}$-vector divergence maximum (Table 3c, column 1). Correlations between these fields were greater than 0.96 for all tracks and both quartiles, implying similar orientations. Further inspection of the magnitudes of the quartiles and mean values of $\mathbf{Q}$-vector divergence revealed the largest differences between the tracks.

Analysis of the midlevel stability quartiles revealed a 


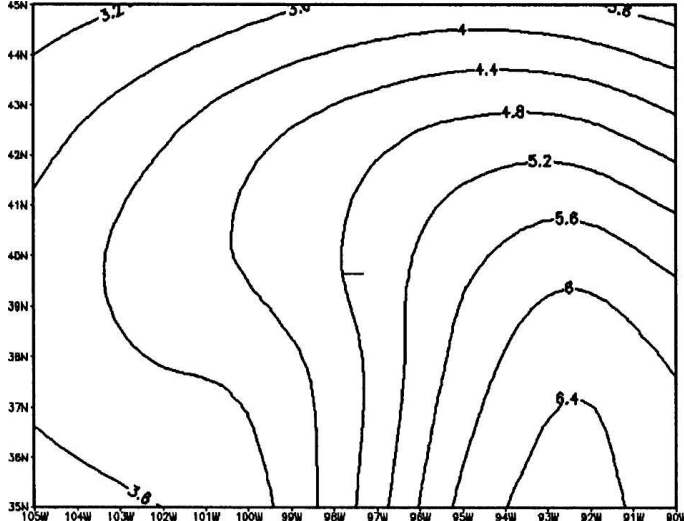

(a)

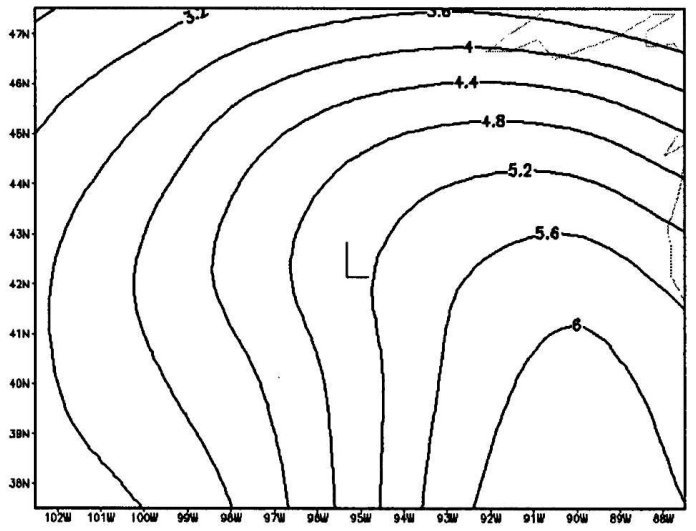

(b)

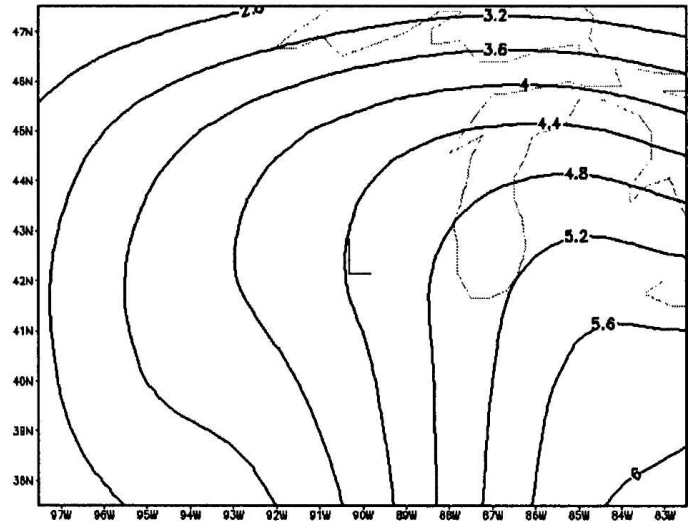

(c)

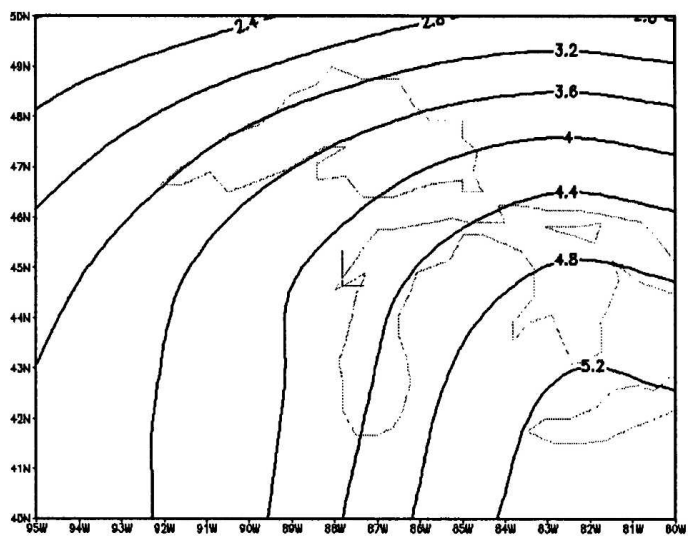

(d)

FIG. 18. Same as in Fig. 17, but for the CO cyclones.

key result: all fields were essentially identical in orientation (correlations $>0.97$ for all quartiles). This led to difficulty in discriminating which cyclone type is being analyzed but, a further inspection of the magnitudes of stability, revealed large differences between the storms in the tracks. It was evident that the EC cyclones were the most stable both in the mean (Table 3d, columns 1 and 4 ), and in the maximum and minimum values of the quartiles (Table 3d, columns 2, 3, 5, and 6). The most unstable storm track type was the $\mathrm{CO}$ cyclone, although the differences between $\mathrm{CO}$ and $\mathrm{AB}$ were small, both in the maximum stability (Table 3d, columns 2 and 3) and maximum instability regions (Table $3 \mathrm{~d}$, columns 5 and 6). This result led to difficulty distinguishing between the $\mathrm{CO}$ and $\mathrm{AB}$ cyclones based on midlevel stability and supported previous statements about their similarity, which is thought to be a result of their similar longitudinal location throughout their evolution.

For low-level stability (Table 3e), the EC cyclones were the most stable for both the mean storm type and the quartiles. Correlations between all three tracks remained quite high ( $>0.97$ for all tracks), implying difficulty in determining the track type based strictly on the orientation of the field. However, a comparison of the magnitudes of the stronger $\mathrm{AB}$ and $\mathrm{CO}$ cyclones revealed that the $\mathrm{CO}$ cyclones maintained the most unstable profile (Table 3e, columns 1-3) and had a more stable maximum stability region (columns 4-6), implying the highest stability gradients exist in the $\mathrm{CO}$ cyclone. This result could not be quantified in the midlevel stability fields since little to no variation between the $\mathrm{AB}$ and $\mathrm{CO}$ cyclones existed. Overall, the low-level stability results suggested the largest stability gradients existed in the $\mathrm{CO}$ cyclones, while the EC cyclones were the most stable overall. The AB cyclones are similar in magnitude to the $\mathrm{CO}$ cyclones, but the gradient was weaker.

For moisture content (Table 3f), the AB cyclones showed significantly less moisture than the cyclones in the other two tracks (on the order of $33 \%$ from the mean $\mathrm{CO}$ cyclone, which has the highest specific humidity). Orientations between the fields were nearly identical (correlations $>0.97$ for all tracks), implying analysis of the magnitude was required to distinguish between the tracks. The $\mathrm{CO}$ cyclones revealed the highest moisture content throughout the fields, although 


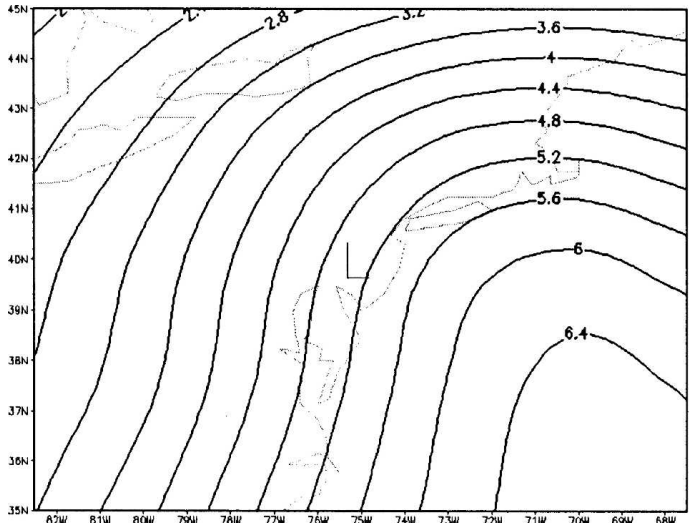

(a)

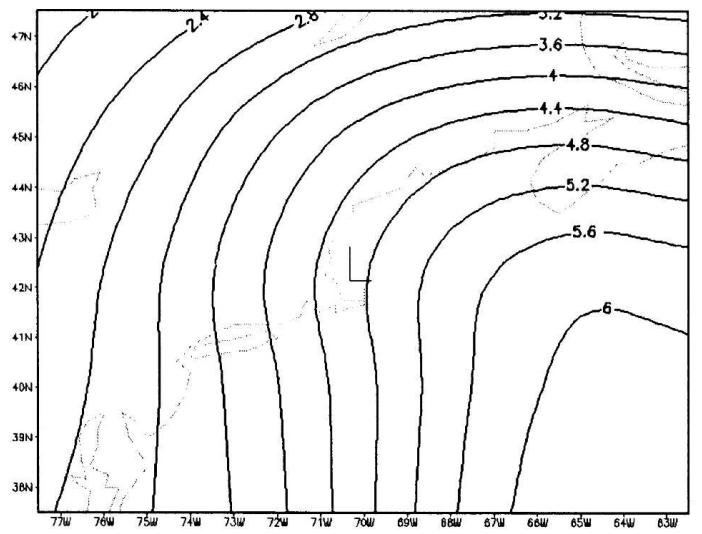

(b)

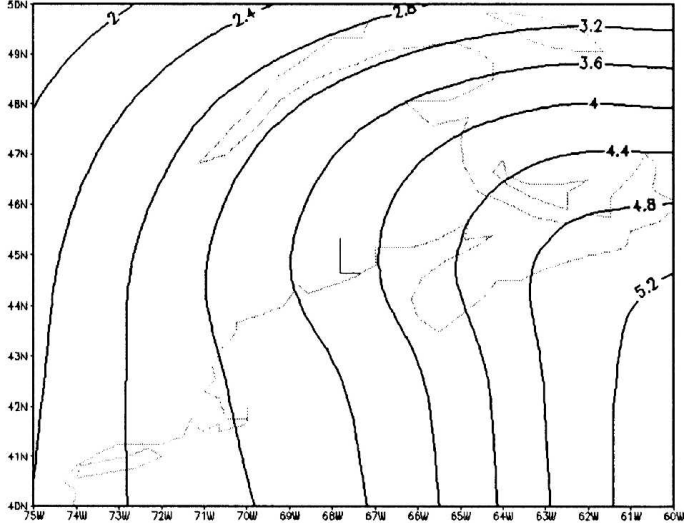

(c)

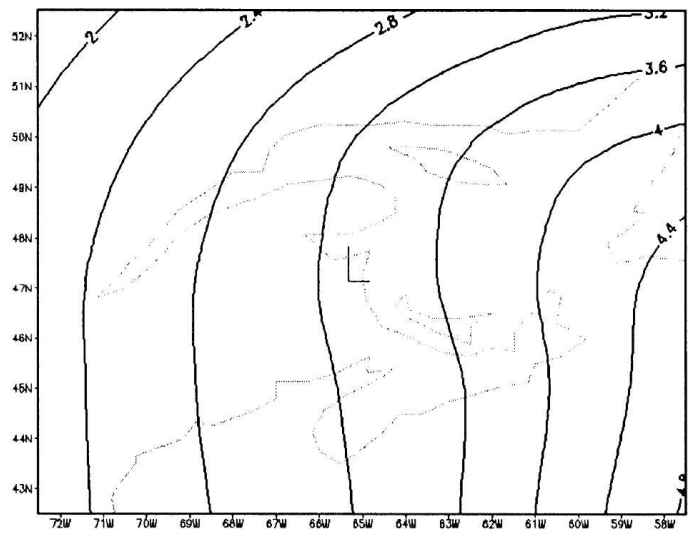

(d)

FIG. 19. Same as in Fig. 17, but for the EC cyclones.

differences between the $\mathrm{CO}$ cyclone and the EC cyclone were less than $10 \%$. These results suggested that the most moisture was present in the $\mathrm{CO}$ cyclone, whereas the $\mathrm{AB}$ cyclone contained much less moisture content than the storms in the other tracks.

\section{h. Synthesis}

The scope of this project was to determine physical and dynamic features of cyclones in each of the three main synoptic storm tracks, determining properties unique to each of the three tracks in an effort to enable discrimination between the storm types based on their given fields. The $\mathrm{AB}$ cyclone maintained several unique characteristics. The $\mathrm{AB}$ cyclones were dominated by midlevel vorticity advection as a means of vertical motion, and in terms of magnitude, the $\mathrm{AB}$ cyclones maintained the weakest vertical motion (based on values of the $\mathbf{Q}$-vector convergence field). Thermal advection was weakest in the $\mathrm{AB}$ cyclone, but differential vorticity advection was stronger than in the EC cyclone. The $\mathrm{AB}$ cyclones maintained the lowest moisture content throughout their temporal sequence, which was an ex- pected result. Stability of the AB and $\mathrm{CO}$ cyclones was indistinguishable, and was more unstable than the EC cyclone. The most important results from analyses of the $\mathrm{AB}$ cyclones were the disparities between the mean fields and the quartiles, as these fields, especially for differential vorticity advection, were the most different of all the tracks. The weak $\mathrm{AB}$ cyclones exhibit no anticyclonic vorticity advection or $\mathbf{Q}$-vector divergence, implying a lack of vigorous vorticity dynamics. Analysis of the three $\mathrm{AB}$ quasigeostrophic mean fields revealed a general eastward motion of the maximum of vertical forcing, a feature not seen for storms in the other two tracks. An overall picture of the $\mathrm{AB}$ cyclone revealed the weakest vertical motion of the three tracks, a general eastward evolution of the dynamical fields in comparison with the CO and EC cyclones, low moisture content, and higher stability than the EC cyclone.

In the $\mathrm{CO}$ cyclone, a general northeastward motion with time was observed. Temperature advection fields appeared similar to those seen in the EC cyclone, but an analysis of magnitude differences demonstrated strong disparities near the $850-\mathrm{hPa}$ frontal boundaries 
TABLE 3. Table of maximum and minimum values of the two quartile fields and the mean fields used for comparison, as well as correlations between the quartiles and the mean fields. The first three columns represent the value of the maximum grid point in the mean field (first column), the 25th quartile (second column; Q-25), and the 75th quartile (third column; Q-75). The second set of three columns represents the minimum values, with the order the same as for the first set of three. The final two columns are correlations between the 25th quartile (first column) and the mean field and the 75th quartile (second column) and the mean field. (a) The 850-hPa temperature advection, (b) the 400-600-hPa differential absolute geostrophic vorticity advection, (c) the 500-hPa Q-vector divergence, (d) the midlevel stability, (e) the low-level stability, and (f) the mean layer specific humidity.

(a) 850-hPa temperature advection

\begin{tabular}{|c|c|c|c|c|c|c|c|c|}
\hline & \multicolumn{3}{|c|}{ Max values } & \multicolumn{3}{|c|}{ Min values } & \multicolumn{2}{|c|}{ Correlations } \\
\hline & Mean & Q-25 & Q-75 & Mean & Q-25 & Q-75 & Q-25 & Q-75 \\
\hline $\mathrm{AB}$ & $1.66 \times 10^{-4}$ & $5.41 \times 10^{-4}$ & $2.64 \times 10^{-4}$ & $-1.87 \times 10^{-4}$ & $-2.96 \times 10^{-4}$ & $-6.44 \times 10^{-5}$ & 0.98 & 0.96 \\
\hline $\mathrm{CO}$ & $1.88 \times 10^{-4}$ & $7.61 \times 10^{-5}$ & $3.08 \times 10^{-4}$ & $-1.51 \times 10^{-4}$ & $-2.77 \times 10^{-4}$ & $-3.99 \times 10^{-5}$ & 0.96 & 0.97 \\
\hline EC & $2.50 \times 10^{-4}$ & $7.25 \times 10^{-5}$ & $3.58 \times 10^{-4}$ & $-2.15 \times 10^{-4}$ & $-3.69 \times 10^{-4}$ & $-9.49 \times 10^{-5}$ & 0.96 & 0.98 \\
\hline
\end{tabular}

(b) 400-600-hPa differential absolute geostrophic vorticity advection

\begin{tabular}{|c|c|c|c|c|c|c|c|c|}
\hline & \multicolumn{3}{|c|}{ Max values } & \multicolumn{3}{|c|}{ Min values } & \multicolumn{2}{|c|}{ Correlations } \\
\hline & Mean & Q-25 & Q-75 & Mean & Q-25 & Q-75 & Q-25 & Q-75 \\
\hline $\mathrm{AB}$ & $1.01 \times 10^{-13}$ & $4.31 \times 10^{-14}$ & $1.41 \times 10^{-13}$ & $-3.97 \times 10^{-14}$ & $-1.01 \times 10^{-13}$ & $1.87 \times 10^{-14}$ & 0.91 & 0.89 \\
\hline $\mathrm{CO}$ & $1.06 \times 10^{-13}$ & $4.98 \times 10^{-14}$ & $1.54 \times 10^{-13}$ & $-5.83 \times 10^{-14}$ & $-1.20 \times 10^{-13}$ & $1.72 \times 10^{-14}$ & 0.94 & 0.93 \\
\hline $\mathrm{EC}$ & $9.82 \times 10^{-14}$ & $3.71 \times 10^{-14}$ & $1.50 \times 10^{-13}$ & $-3.92 \times 10^{-14}$ & $-1.27 \times 10^{-13}$ & $2.99 \times 10^{-14}$ & 0.93 & 0.93 \\
\hline
\end{tabular}

(c) 500-hPa $\mathbf{Q}$-vector divergence

\begin{tabular}{|c|c|c|c|c|c|c|c|c|}
\hline & \multicolumn{3}{|c|}{ Max values } & \multicolumn{3}{|c|}{ Min values } & \multicolumn{2}{|c|}{ Correlations } \\
\hline & Mean & Q-25 & Q-75 & Mean & Q-25 & Q-75 & Q-25 & Q-75 \\
\hline $\mathrm{AB}$ & $6.30 \times 10^{-16}$ & $-6.64 \times 10^{-17}$ & $1.07 \times 10^{-15}$ & $-1.19 \times 10^{-15}$ & $-1.87 \times 10^{-15}$ & $-5.47 \times 10^{-16}$ & 0.98 & 0.96 \\
\hline $\mathrm{CO}$ & $7.96 \times 10^{-16}$ & $-7.49 \times 10^{-17}$ & $1.50 \times 10^{-15}$ & $-1.23 \times 10^{-15}$ & $-1.81 \times 10^{-15}$ & $-4.19 \times 10^{-16}$ & 0.96 & 0.97 \\
\hline EC & $6.95 \times 10^{-16}$ & $-9.94 \times 10^{-17}$ & $1.52 \times 10^{-15}$ & $-1.26 \times 10^{-15}$ & $-1.90 \times 10^{-15}$ & $-4.33 \times 10^{-16}$ & 0.96 & 0.98 \\
\hline
\end{tabular}

(d) Midlevel stability

\begin{tabular}{|c|c|c|c|c|c|c|c|c|}
\hline & \multicolumn{3}{|c|}{ Max values } & \multicolumn{3}{|c|}{ Min values } & \multicolumn{2}{|c|}{ Correlations } \\
\hline & Mean & Q-25 & Q-75 & Mean & Q-25 & Q-75 & Q-25 & Q-75 \\
\hline $\mathrm{AB}$ & -9.6 & -11.3 & -8.1 & -13.2 & -15.3 & -11.4 & 0.99 & 0.99 \\
\hline $\mathrm{CO}$ & -9.5 & -11.3 & -7.9 & -13.0 & -15.1 & -10.9 & 0.98 & 0.97 \\
\hline EC & -10.4 & -12.0 & -8.4 & -13.9 & -15.4 & -12.0 & 0.98 & 0.99 \\
\hline
\end{tabular}

(e) Low-level stability

\begin{tabular}{|c|c|c|c|c|c|c|c|c|}
\hline & \multicolumn{3}{|c|}{ Max values } & \multicolumn{3}{|c|}{ Min values } & \multicolumn{2}{|c|}{ Correlations } \\
\hline & Mean & Q-25 & Q-75 & Mean & Q-25 & Q-75 & Q-25 & Q-75 \\
\hline $\mathrm{AB}$ & -7.7 & -9.1 & -5.5 & -11.1 & -13.5 & -9.0 & 0.99 & 0.96 \\
\hline $\mathrm{CO}$ & -7.2 & -8.8 & -4.1 & -11.5 & -13.9 & -9.1 & 0.98 & 0.98 \\
\hline $\mathrm{EC}$ & -8.1 & -9.3 & -6.6 & -11.6 & -13.9 & -9.4 & 0.99 & 0.97 \\
\hline
\end{tabular}

(f) Mean layer specific humidity

\begin{tabular}{|c|c|c|c|c|c|c|c|c|}
\hline & \multicolumn{3}{|c|}{ Max values } & \multicolumn{3}{|c|}{ Min values } & \multicolumn{2}{|c|}{ Correlations } \\
\hline & Mean & Q-25 & Q-75 & Mean & Q-25 & Q-75 & Q-25 & Q-75 \\
\hline $\mathrm{AB}$ & $4.16 \times 10^{-3}$ & $2.67 \times 10^{-3}$ & $5.72 \times 10^{-3}$ & $1.61 \times 10^{-3}$ & $8.77 \times 10^{-4}$ & $2.31 \times 10^{-3}$ & 0.99 & 0.99 \\
\hline $\mathrm{CO}$ & $6.14 \times 10^{-3}$ & $4.57 \times 10^{-3}$ & $7.67 \times 10^{-3}$ & $2.40 \times 10^{-3}$ & $1.32 \times 10^{-3}$ & $3.28 \times 10^{-3}$ & 0.98 & 0.99 \\
\hline EC & $5.54 \times 10^{-3}$ & $3.89 \times 10^{-3}$ & $7.34 \times 10^{-3}$ & $1.73 \times 10^{-3}$ & $1.01 \times 10^{-3}$ & $2.28 \times 10^{-3}$ & 0.97 & 0.99 \\
\hline
\end{tabular}

when compared with the EC cyclone. WAA was stronger in the $\mathrm{CO}$ cyclones than in the $\mathrm{AB}$ cyclones, but $\mathrm{CAA}$ remained stronger in the $\mathrm{AB}$ cyclone due to its ability to entrain a stronger Arctic air mass. Differential absolute geostrophic vorticity advection was most vig- orous in this storm type, and the stronger $\mathrm{CO}$ cyclones exhibited much larger CVA and AVA than storms in the other two tracks. As with the AB cyclones, no AVA existed in weak $\mathrm{CO}$ cyclones, suggesting little to no vorticity dynamics in the weak $\mathrm{CO}$ cyclones. The Q- 
vector fields revealed that the $\mathrm{CO}$ cyclones have the second-strongest forcing of the three tracks, although the differences between the $\mathrm{CO}$ and $\mathrm{AB}$ cyclones are less than $10 \%$. The stronger $\mathrm{CO}$ cyclones tended to exhibit the weakest vertical forcing of the three tracks (Table 3c, column 5), while the weaker CO cyclones showed no sign of $\mathbf{Q}$-vector divergence (no sinking motion from an oncoming anticyclone). The $\mathrm{CO}$ cyclones had more instability than the EC cyclones, and the magnitude of this instability was similar to the $\mathrm{AB}$ cyclone (a feature thought to be a result of their similar longitudinal location). The $\mathrm{CO}$ cyclones maintained the highest moisture content of the three tracks, attributable to the generally warmer temperatures in these systems and a large moisture input from the Gulf of Mexico. The CO cyclones, as with the AB cyclones, demonstrated a westward tilt with height in both the vorticity advection and $\mathbf{Q}$-vector divergence fields, as was expected from previous work.

The EC cyclone, like the CO cyclone, evolved northeastward with time, a major difference between it and the $\mathrm{AB}$ cyclone. Thermal advection in the $\mathrm{EC}$ cyclone was much stronger than for storms in the other two tracks (up to $40 \%$ ). Large differences between the CO and EC cyclone existed near the $850-\mathrm{hPa}$ frontal boundary, aiding in discriminating between the different storms. The weak EC cyclones exhibited stronger thermal advection than was seen in the other two tracks, and strong storms almost doubled the thermal advection magnitudes compared with the weaker $\mathrm{AB}$ and $\mathrm{CO}$ cyclones. In contrast with the thermal advection field, vorticity advection in the EC cyclone was the weakest of the three tracks, although these differences were less than $10 \%$. Vorticity advection in the strong $\mathrm{EC}$ cyclones was stronger than seen in the $\mathrm{AB}$ cyclones; however, the $\mathrm{CO}$ cyclones maintained the strongest vorticity advection magnitudes throughout. The EC cyclone maintained the strongest vertical forcing (derived from $\mathbf{Q}$-vector convergence results), although the forcing differences were minute when compared with the other two tracks (less than 10\%). The strong EC cyclones had the largest values of $\mathbf{Q}$-vector divergence (sinking motion) of the three tracks, as well as the strongest $\mathbf{Q}$-vector convergence (rising motion). This implied that, overall, midlevel vertical motion was strongest in the EC cyclone. All mean fields appeared similar to their quartile counterparts, supported by high correlations of over 0.9 for all relations but one ( 0.89 in that case). Moisture content of the EC cyclone was higher than for the $\mathrm{AB}$ cyclone, but the strong Arctic push west of the low pressure system led to lower moisture content on the western and northwestern side of the system. The EC cyclones were found to be the most stable of the three tracks at both low and midlevels as well.

Numerous key distinctions between storms in the three tracks were determined from this analysis. These variations enable the determination of which track a storm resided in based solely on its diagnostic variable fields.

\section{Conclusions}

The goal of this project was to determine commonalities and differences in synoptic storm track dynamics and physical properties in the three major storm tracks that affect North America for all seasons. Mean fields were created to obtain representative patterns of the six diagnostic variables used in the analysis. The $\mathbf{Q}$-vector divergence at $500 \mathrm{hPa}$, the temperature advection at $850 \mathrm{hPa}$, and the differential geostrophic absolute vorticity advection between 400 and $600 \mathrm{hPa}$ were computed to quantitatively and qualitatively diagnose quasigeostrophic dynamics in the storm tracks. Mean layer specific humidity was computed as a measure of moisture content of the storms, while low- and midlevel stability were computed to complement the vertical motion analysis of the quasigeostrophic variables. Mean fields were consistent with the expected physical properties of each synoptic storm track. In terms of magnitude, the EC cyclones maintained the strongest thermal advection (almost 100\% stronger WAA and $50 \%$ stronger CAA than the CO cyclones at $t_{0}$, the time of lowest surface pressure). CVA was weakest in the EC cyclone though, while the CO cyclone maintained the strongest CVA of the three tracks. The resulting Q-vector divergence fields implied the strongest rising motion was present in the EC cyclone, and the $\mathbf{Q}$-vector convergence maxima was collocated with the maxima of CVA, suggesting midlevel vertical forcing was strongly dependent on the vorticity advection at midlevels for all tracks. The $\mathrm{AB}$ cyclones showed the smallest thermal advection and second weakest vorticity advection, as well as the least vertical motion from its limited $\mathbf{Q}$-vector convergence maxima. These results were expected since the $\mathrm{AB}$ cyclone has fewer sources of baroclinicity when compared with storms in the other two tracks.

The stability fields at midlevels revealed maximum instability regions corresponding with the warmest midlevel air, and the gradient of stability was broad in the midlevels. This result supports the use of quasigeostrophic theory as an analysis tool at midlevels. Lowlevel stability fields appeared considerably different than at midlevels, with a region of maximum instability south of the surface low and a trough of maximum 
stability due west of the low. This southern region was a result of the warmer air in the warm sector of the low-level cyclone, and the western region was a result of the surge of cold air behind the low-level cyclones. The $\mathrm{AB}$ cyclones were the most unstable at midlevels, and at low levels the $\mathrm{CO}$ cyclones were the most unstable. These differences were attributed to the disparities in low-level thermal advection in the $\mathrm{CO}$ cyclone versus the other two, and the midlevel dynamics of the $\mathrm{AB}$ cyclone being stronger than in the other two types. The EC and CO cyclones contained the largest specific humidity at all times, and specific humidity in all three tracks decreased with time due to loss of precipitable water and cool, dry air being advected in with the trailing anticyclone. All three storm tracks maintained a similar orientation of maximum and minimum moisture, with a maximum noted east-southeast of the surface low and minimum noted west of the surface low.

Correlations were computed between the different storm tracks to diagnose pattern differences between the fields, and magnitudes of the quartiles were computed in order to analyze variability within each track. Strong and weak cyclones were identified from the quartiles as well, and all mean variables were found to be highly correlated with the quartile fields. This led to a unique pattern or "fingerprint" of each diagnostic variable for storms in each track at the time of strongest surface dynamics $\left(t_{0}\right)$. Analysis of the magnitudes of these quartiles and comparison with the mean fields revealed large variability in the diagnostic variables for each track, a result not previously quantified in the synoptic literature. These fingerprints, combined with knowledge of magnitude differences of the three tracks, allowed for the discrimination between storms in each of the tracks from the diagnostic variable fields.

It is unknown whether fingerprints of storm tracks could have been determined at times other than $t_{0}$. A more robust computation of static stability that included a vertical derivative term could add additional insight as to the unexpected results of the stability fields. The Lagrangian viewpoint presented in this work allows for numerous applications of the methodology, including representing synoptic storms and their tracks in climate models. Moreover, these results can be applied to determine which track type is being observed, a result that could be integrated into numerical modeling for better forecast accuracy. Ultimately, the ability to discriminate which storm track a particular cyclone developed in, without examining a geographical map, could be useful as a data mining tool for synopticians and a springboard for investigating why these storms behave the way they do.
Acknowledgments. This work was funded by Williams Grant AGR062001 and by the Cooperative Institute for Mesoscale Meteorological Studies (CIMMS). We wish to thank Zewdu Tessema for his help with the production of graphical output in GrADS, as well as Drs. Howard B. Bluestein and David M. Schultz for their invaluable insight on synoptic storm dynamics, and Dr. Peter J. Lamb for supporting this work and offering the opportunity to undertake this analysis. Special thanks are extended to Dr. Lance Bosart for his acumen on the synoptic interpretation of diagnostic variables and to the reviewers for their role in improving this work for publication.

\section{REFERENCES}

Barnes, S. L., 1986: On the accuracy of omega diagnostic computations. Mon. Wea. Rev., 114, 1664-1680.

—, and B. R. Colman, 1994: Diagnosing an operational numerical model using Q-vector and potential vorticity concepts. Wea. Forecasting, 9, 85-102.

Bell, G. D., and L. F. Bosart, 1993: A case study diagnosis of the formation of an upper- level cutoff circulation over the eastern United States. Mon. Wea. Rev., 121, 1635-1655.

— and —_ 1994: Midtropospheric closed cyclone formation over the southwestern United States, the eastern United States, and the Alps. Mon. Wea. Rev., 122, 791-813.

Bierly, G. D., and J. A. Harrington Jr., 1995: A climatology of transition season Colorado cyclones: 1961-1990. J. Climate, 8, 853-863.

Bluestein, H. B., 1992: Synoptic-Dynamic Meteorology in Midlatitudes. Vol. I. Principles of Kinematics and Dynamics, Oxford University Press, $431 \mathrm{pp}$.

—. 1993: Synoptic-Dynamic Meteorology in Midlatitudes. Vol. II. Observations and Theory of Weather Systems, Oxford University Press, $594 \mathrm{pp}$.

Bosart, L. F., 1981: The Presidents' Day snowstorm of 18-19 February 1979: A subsynoptic-scale event. Mon. Wea. Rev., 109, 1542-1566.

_ and S. C. Lin, 1984: A diagnostic analysis of the Presidents' Day storm of 1979. Mon. Wea. Rev., 112, 2148-2177.

Bowie, E. H., and R. H. Weightman, 1914: Types of cyclones of the United States and their average movements. Mon. Wea. Rev., 42 (Suppl. 1), 3-37, + 114 charts.

Boyle, J. S., and L. F. Bosart, 1986: Cyclone-anticyclone couplets over North America. Part II: Analysis of a major cyclone event over the eastern United States. Mon. Wea. Rev., 114, 2432-2465.

COLA, cited 2005: Grid Analysis and Display System (GrADS). [Available online at http://grads.iges.org/grads/.]

Dodd, A. V., 1965: Dew point distribution in the contiguous United States. Mon. Wea. Rev., 93, 113-122.

Fawcett, E. B., and H. K. Saylor, 1965: A study of the distribution of weather accompanying Colorado cyclogenesis. Mon. Wea. Rev., 93, 359-367.

Gibson, J., P. Kållberg, S. Uppala, A. Nomura, A. Hernandez, and E. Serrano, 1997: ERA description. ECMWF Re-Analysis Project Rep. Series 1, ECMWF, Reading, United Kingdom, $72 \mathrm{pp}$. 
Gyakum, J. R., 1983: On the evolution of the $Q E I I$ storm. I: Synoptic aspects. Mon. Wea. Rev., 111, 1137-1155.

- 1991: Meteorological precursors to the explosive intensification of the QE II storm. Mon. Wea. Rev., 119, 1105-1131.

— , P. J. Roebber, and T. A. Bullock, 1992: The role of antecedent surface vorticity development as a conditioning process in explosive cyclone intensification. Mon. Wea. Rev., 120, $1465-1489$.

Hodges, K. I., B. J. Hoskins, J. Boyle, and C. Thorncroft, 2003: A comparison of recent reanalysis datasets using objective feature tracking: Storm tracks and tropical easterly waves. Mon. Wea. Rev., 131, 2012-2037.

Hoskins, B. J., I. Draghici, and H. C. Davies, 1978: A new look at the omega-equation. Quart. J. Roy. Meteor. Soc., 104, 31-38.

Hutchinson, T. A., 1995: An analysis of NMC's nested grid model forecasts for Alberta clippers. Wea. Forecasting, 10, 632-641.

Insightful Corporation, 2002: Splus Version 6.1. University of Oklahoma.

Jusem, J. C., and R. Atlas, 1998: Diagnostic evaluation of vertical motion forcing mechanisms by using Q-vector partitioning. Mon. Wea. Rev., 126, 2166-2184.

Kalnay, E., and Coauthors, 1996: The NCEP/NCAR 40-Year Reanalysis Project. Bull. Amer. Meteor. Soc., 77, 437-471.

Kanamitsu, M., W. Ebisuzaki, J. Woolen, J. Potter, and M. Fiorino, 1999: An overview of reanalysis-2. Proc. Second Int. Conf. on Reanalyses, Reading, United Kingdom, WCRP, $1-4$.

Keshishian, L. G., and L. F. Bosart, 1987: A case study of extended East Coast frontogenesis. Mon. Wea. Rev., 115, 100117.

,-- , and W. E. Bracken, 1994: Inverted troughs and cyclogenesis over interior North America: A limited regional climatology and case studies. Mon. Wea. Rev., 122, 565-607.

Keyser, D., B. D. Schmidt, and D. G. Duffy, 1992: Quasigeostrophic vertical motions diagnosed from along and crossisentrope components of the Q-vector. Mon. Wea. Rev., 120, 731-741.

Klein, W. H., 1951: A hemispheric study of daily pressure variability at sea level and aloft. J. Meteor., 8, 332-346.

Konrad, C. E., II, 1997: Synoptic-scale features associated with warm season heavy rainfall over the interior southeastern United States. Wea. Forecasting, 12, 557-571.

Lupo, A. R., P. J. Smith, and P. Zwack, 1992: A diagnosis of the explosive development of two extratropical cyclones. Mon. Wea. Rev., 120, 1490-1523.

Marshment, R. A., and L. H. Horn, 1986: Spring season Colorado cyclones. Part II: Composites of atmospheric moisture and moist static stability. J. Appl. Meteor., 25, 744-752.

Mercer, A., 2005: Analysis of three synoptic storm tracks in the United States. M.S. thesis, School of Meteorology, University of Oklahoma, $235 \mathrm{pp}$.

Pagnotti, V., and L. F. Bosart, 1984: Comparative diagnostic case study of East Coast secondary cyclogenesis under weak versus strong synoptic-scale forcing. Mon. Wea. Rev., 112, 5-30.
Reitan, C. H., 1974: Frequencies of cyclones and cyclogenesis for North America, 1951- 1970. Mon. Wea. Rev., 102, 861-868.

Richman, M. B., P. J. Lamb, and J. R. Angel, 1991: Multivariate statistical analysis of precipitation associated with North American winter storm tracks. Preprints, Fifth Conf. on Climate Variations, Denver, CO, Amer. Meteor. Soc., 47-53.

,$- \ldots$, A. Zangvil, and J. R. Angel, 1992: Multivariate statistical analysis of precipitation associated with North American storm tracks. Preprints, 12th Conf. on Probability and Statistics in the Atmospheric Sciences, Toronto, ON, Canada, Amer. Meteor. Soc., 277-283.

Rolfson, D. M., and P. J. Smith, 1996: A composite diagnosis of synoptic-scale extratropical cyclone development over the United States. Mon. Wea. Rev., 124, 1084-1099.

Sanders, F., 1987: A study of $500 \mathrm{mb}$ vorticity maxima crossing the East Coast of North America and associated surface cyclogenesis. Wea. Forecasting, 2, 70-83.

_ , and B. J. Hoskins, 1990: An easy method for estimation of Q-vectors from weather maps. Wea. Forecasting, 5, 346-353.

Schultz, D. M., and C. A. Doswell III, 2000: Analyzing and forecasting Rocky Mountain lee cyclogenesis often associated with strong winds. Wea. Forecasting, 15, 152-173.

Serreze, M. C., R. G. Barry, and J. E. Walsh, 1995: Atmospheric water vapor characteristics at $70^{\circ} \mathrm{N}$. J. Climate, 8, 719-731.

_, F. Carse, R. G. Barry, and J. C. Rogers, 1997: Icelandic low cyclone activity: Climatological features, linkages with the NAO, and relationships with recent changes in the Northern Hemisphere circulation. J. Climate, 10, 453-464.

Servranckx, R., 1988: Divergence and vertical motion in a typical mid-latitude frontal cyclone. Preprints, Palmén Memorial Symp. on Extratropical Cyclones, Helsinki, Finland, Amer. Meteor. Soc., 153-156.

Smith, P. J., C. H. Tsou, and M. N. Baker, 1988: Static stability variations during a winter marine cyclone development. Preprints, Palmén Memorial Symp. on Extratropical Cyclones, Helsinki, Finland, Amer. Meteor. Soc., 132-135.

Stooksbury, D. E., and P. J. Michaels, 1991: Cluster analysis of southeastern U.S. climate stations. Theor. Appl. Climatol., 44, 143-150.

Whittaker, L. M., and L. H. Horn, 1981: Geographical and seasonal distribution of North American cyclogenesis, 19581977. Mon. Wea. Rev., 109, 2312-2322.

—, and —, 1984: Northern Hemisphere extratropical cyclone activity for four mid-season months. J. Climatol., 4, 297-310.

Wichansky, P. S., and R. P. Harnack, 2000: A diagnosis of tropospheric effects upon surface precipitation for a sample of East Coast snowstorms. Wea. Forecasting, 15, 339-348.

Wilks, D. S., 1995: Statistical Methods in the Atmospheric Sciences. Academic Press, 465 pp.

Zishka, K. M., and P. J. Smith, 1980: The climatology of cyclones and anticyclones over North America and surrounding ocean environs for January and July, 1950-1977. Mon. Wea. Rev., 108, 387-401. 
Copyright of Monthly Weather Review is the property of American Meteorological Society and its content may not be copied or emailed to multiple sites or posted to a listserv without the copyright holder's express written permission. However, users may print, download, or email articles for individual use. 